\title{
Serious Gaming of Logistics Management in Pediatric Emergency Medicine
}

\author{
Cevin Zhang ${ }^{1}$, Karin Pukk Härenstam ${ }^{2}$, Sebastiaan Meijer ${ }^{3}$, Adam Darwich ${ }^{1}$ \\ ${ }^{1}$ Division of Logistics and Health informatics, Department of Biomedical Engineering \\ and Health Systems, KTH Royal Institute of Technology, Sweden (Hälsovägen 11C, \\ Huddinge 14156, Sweden) \\ \{chenzh,darwich\}@kth.se \\ ${ }^{2}$ Pediatric Emergency Department, Karolinska University Hospital, Sweden, \\ karin.pukk@ki.se \\ ${ }^{3}$ Department of Biomedical Engineering and Health Systems, KTH Royal Institute of \\ Technology,Sweden, smeijer@kth.se
}

\section{Abstract}

Access blocks throughout the entire healthcare system and overcrowding issues are pervasive in many emergency departments where the coordination and strategic management of resources could be supported by serious games and simulations approaches. However, existing studies have not addressed the reciprocal relation between patient inflow and working systems in serious games design in order to reflect the logistical features of an emergency department and to facilitate the players improve the work performance of the system. To address the issue, this paper presents a serious game based on a multi-method simulation approach of complex healthcare processes as well as the game mechanics selected to promote understanding the logistical features of an ED, which points to the next level of conducting simulations or gaming aimed for training decision making skills in operative environments. Results of the experiment confirmed that the serious game encouraged participants to proactively manage the human resources of the emergency department. Certain managerial recommendations can be made: a patient flow multiplier of 120\% could lead to a significant erosion of the system's defensive ability; however, proactive anticipation from management is the key for making an emergency organization more resilient.

Keywords: Serious game, simulation, pediatric emergency department, logistics management, work system;

\section{$1 \quad$ Introduction}

Emergency departments (EDs) are one of those healthcare organizations receiving the widest attention in terms of strategic initiatives and have attracted more attention towards cultivating sustainable practices for imbalance settlement in the workplace [1][2]. There are two perspectives on this problem. From the work system perspective, based on a survey study of more than 200 employees working in ambulance services and emergency rooms, career changes due to heavy workload was reported by one in three emergency personnel, with recommendations on reducing the physical workload and implementing better management [3]. From the patient flow perspective, in recent years, there has been a steady rise in the number of ED patient visits in Sweden [4] and worldwide due to increased complexity and aging populations. Crowding due to external reasons, e.g., 
underused services or a lack of availability of primary care services, is a growing problem [5]. A European Commission report determined that solving this issue is rooted in optimizing patient flows [6]. This difficult situation in the healthcare working environment calls for more coordination and a change in management efforts in order to improve the situation for both care receivers and care providers. A multitude of operational issues add more value to interwoven resource management and the engineering of improvements at the organizational level as well as strategic initiatives to eliminate the low-resource circumstances and long waiting times.

Serious games and interactive simulations as an intervention approach in healthcare constitute a simulation of scenarios aimed for aiding rehabilitation processes [7], improving the quality of care [8] and promoting physical activities [9]. In emergency medicine, serious games are either designed for improving crisis management skills upon escalating event, or used in simulation-based teamwork training activities for steering staff's attitudes and learning on the reaction level [10][11]. In case of unfulfilled requirement from the participant side, consequences in the form of fewer rewards earned and instructions will be presented for adjustments. In comparison to non-game based learning methods, serious game-based training is effective in enhancing cognitive abilities and enabling active learning and hence has been increasingly used in medical education in a recent decade [12].

Serious games are not provisionally accepted by improving the logistics management in ED. This is due to the fact that few interactive simulations represent the production system and accordingly select game mechanics which facilitates the handling unexpected perturbations from demand-supply gaps. However, EDs nowadays are vulnerable than ever to management issues in workplaces given the increasing number of hospital visits and a high resource turnover required to discharge patients faster. Patient upsurges and access blocks that are brought in from the entire healthcare system could be sources of production pressures. High workloads with low-resource settings in the healthcare logistics system not only decrease the quality of care, but also disappoint employees from being productive [13][14] and hence erodes production system resilience. As a result, negative consequences such as occupational burnout, elevated workloads and overcrowding put pressure on the planning and management of human resources.

The potential deployment of logistics management knowledge and concepts in dynamic healthcare environments calls for research on simulation and gaming techniques [15]. Based on empirical data of modelled systems, several recent simulation studies elaborated on how work system mechanisms could be developed in virtual scenarios. Fragapane et al. investigated the impact of logistical flow changes in a hospital's automotive goods vehicle system on extending the operational time horizon [16]. The results showed that simulation with interactive components was a valid method for testing different scenarios and improve the logistical performance of the internal delivery system by highlighting operational constraints in dynamic environments encountered in hospitals. Cerfon et al. developed and evaluated a virtual research environment based on modelling facilities, procedures and resources in the context of ED crowding. The virtual ED comprised 6 types of facilities, 2 types of human resources and 15 undergoing care components for 12 explicitly modeled patients [17]. Potential research may investigate gaming methods to test ED management approaches that fulfil quality of care objectives, including maintaining the resilience of the production system and considering the composition of patient flows. Similar to these studies, this paper is based on real data from ED resource planning system to propose process-simulation mapping documents.

Therefore, the aim of this study is to answer the following research question:

Based on detailed information on patient inflow, tasks and resources, how could a serious game be designed in order to reflect the logistical features of the ED and to facilitate the players improve the work performance of the system?

The outline of this paper is as followings. Previous studies on simulation, gaming and modelling methods for operation management in ED are summarized in Section 2, followed by the presentation of an activity-based diagram based on empirical data in 
Section 3 and the serious game design and the simulation gaming process in Section 4, a procedure illustrated in Figure 1. Scenarios are simulated to investigate the impact of changing the patient inflow volumes and an operating hours reduction as test queries. In Section 5, the implications of the simulation and gaming outcomes are presented and analysed based on the application case. Section 6 concludes the paper with a discussion of the gaming outcomes compared to simulation predictions, limitations and their potential for decision support of ED management.

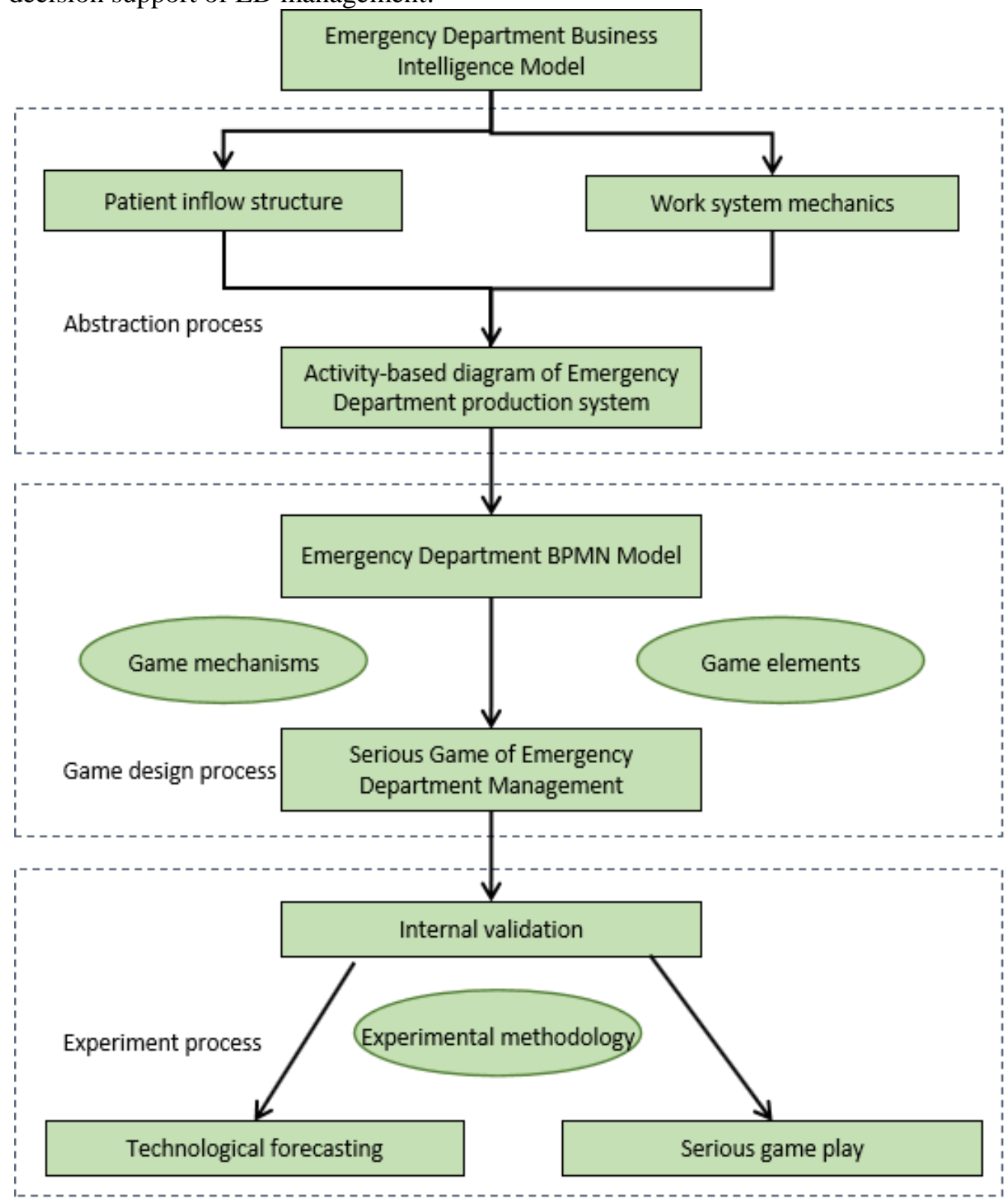

Figure 1. Solution procedure of modeling, simulation and experiment processes for circumventing logistics management problems in ED

\section{Knowledge gaps in the literature and the contributions of this study}

Management tools have explored different practices for managing resources. A wide variety of decision support systems or visualized models have been used to improve the coordination/dispatching of ambulances in emergency care [18]. In previous studies, Oostveen et al. evaluated a workforce planning tool and found difficulties in directly 
connecting the patient classification system to detailed staffing and scheduling on a daily basis [19]. Being informed about the situations and detailed information about the work, as presented in studies by Greenfield et al., will help with review performance, staff management and the delivery of care and will support organizational learning [20]. Knowledge management tools that facilitate transfer and learning are promising but need to be built on real-world data [21].

There is no commonplace framework for building in the heuristics of an ED production system into virtual environments such as serious games, although healthcare simulation has been integrated in training and education. Most researches relied on a few patient entries over a short time horizon or a limited analysis of the resource configuration hinders a comprehensive analysis of potential resource management strategy changes in various patient inflow situations. Furthermore, there is a lack of systematic modelling of both processes in service-based organizations and individuals' responses to environments based on a comprehensive set of empirical data, although simulation games are often considered to obtain management indications [22][23][24].

Specifically on modelling ED patient flows, there have been few advances with regard to the simulating the interactive relationship between hospital visits and logistics management within work systems. Using flow charts as a reference for building a discrete-event simulation, Olsson and Aronsson mapped out the main activities of an acute visit [25] to the hospital in Skåne, Sweden. However, their work included a limited variety of tasks. Codrington-Virtue et al. used advanced clustering tools for the grouping of patient flows using a discrete-event simulation model, where arrival pattern accuracy was considered the most important issue [26]. With application to another Swedish acute center in Vrinnevi Hospital, Haugen and Nillson aimed to achieve a 4-hour maximum stay for $80 \%$ of the arriving patients [27]. A simulation model was created accordingly. Among several scenarios, the authors addressed the work process. However, the work system was not fully represented. Through modeling the implementation of stroke thrombolysis and fast track strategy, Pitt et al. and Maull et al. demonstrated the medical benefits of using simulations [28] [29]. Business intelligence was based on a simplified flow chart without information on activities or tasks for the personnel. Bowers et al. are one of few to have modeled the patient flows using an activity-based method, including transport to services, radiology, consultation, laboratory and release [30]. However, the framework is not sufficiently flexible to analyze access blocks since the modeled pathway can be easily violated in reality. In earlier work, researchers proposed a brand new simulation and gaming structure for regional pediatric patient flows using agent-based simulation and a discrete-event simulation [31]. However, the focus was on coordination between hospitals. The decision support system for addressing individual resource planning inside children's hospitals needs to be expanded with activity-based alleviation of the care production system in emergency medicine. Nevertheless, there have been few interactive simulations based on detailed modeling of care production mechanisms and real flow data to inform the stated strategizing process as illustrated in Table 1.

These tools or models facilitate the management of patient inflow issues, including diversion control, referral controls, care pathways, and modeling through the use of simulation. However, they supply fewer opportunities for considering the impact of patient flows on employees in ED. Little attention has been given to the more complex nature of resource management, including shifts, the running of tasks, organizational structures, alarms for emergency situations, and queue placing according to priorities. The lack of data hinders the development of simulation models that could form the core of decision support systems that build in the heuristics of the working environment and support situational awareness among work systems. There is still much to be done to critically assess resource availability, initiatives for a faster-discharging process, and the ED logistics management strategy to patient inflow surges. 
Table 1. Summary of recent simulation and gaming researches of logistics management in the healthcare context.

\begin{tabular}{|c|c|c|c|c|c|c|c|c|c|c|c|c|}
\hline \multirow[t]{2}{*}{ Articles } & \multicolumn{2}{|c|}{ Method } & \multicolumn{4}{|c|}{ Strategy-level problem addressed } & \multicolumn{2}{|c|}{$\begin{array}{l}\text { Activity- } \\
\text { based } \\
\text { modeling }\end{array}$} & \multicolumn{2}{|c|}{$\begin{array}{c}\text { Consideration } \\
\text { of work system } \\
\text { mechanisms }\end{array}$} & \multicolumn{2}{|c|}{$\begin{array}{c}\text { Suggestions for } \\
\text { healthcare human } \\
\text { resource } \\
\text { planning/management }\end{array}$} \\
\hline & Gaming & Simulation & $\begin{array}{c}\text { Capacity } \\
\text { management }\end{array}$ & $\begin{array}{c}\text { Patient } \\
\text { flows }\end{array}$ & $\begin{array}{c}\text { Bed } \\
\text { allocation }\end{array}$ & $\begin{array}{c}\text { Better } \\
\text { work } \\
\text { system }\end{array}$ & Yes & No & Yes & No & Yes & No \\
\hline$[25]$ & No & $\begin{array}{c}\text { Discrete } \\
\text {-event }\end{array}$ & & $\star$ & & & & $\star$ & & $\star$ & & $\star$ \\
\hline [27] & No & $\begin{array}{l}\text { Discrete } \\
\text {-event }\end{array}$ & $\star$ & $\star$ & & & & $\star$ & & $\star$ & $\star$ & \\
\hline [28] & No & $\begin{array}{c}\text { Discrete } \\
\text {-event }\end{array}$ & & $\star$ & & & & $\star$ & & $\star$ & & $\star$ \\
\hline [29] & No & $\begin{array}{c}\text { Discrete } \\
\text {-event }\end{array}$ & & $\star$ & & & & $\star$ & & $\star$ & & $\star$ \\
\hline$[30]$ & No & $\begin{array}{l}\text { Discrete } \\
\text {-event }\end{array}$ & & $\star$ & & & & $\star$ & & $\star$ & & $\star$ \\
\hline$[31]$ & Yes & Hybrid & & $\star$ & $\star$ & $\star$ & & $\star$ & $\star$ & & $\star$ & \\
\hline
\end{tabular}


To address these knowledge gaps while shortening the lengthy attempt to design and develop serious games and simulation applications, this study aimed to construct an activity-based framework supported by a comprehensive set of empirical data. The framework will serve as a standard for corporate simulation and gaming development for handling management issues in ED. Following the development of a process-simulation mapping document, a serious game for the potential adjustment of health human resource practices and patient inflow scenarios was designed to provide managerial suggestions for a pediatric emergency center in an urban area of Stockholm, Sweden. The core of the serious game is the simulation of complex processes in health service provision. In accordance to this paper's aim, the objective of the serious game is to encourage the player to utilize decision making skills and to improve work system performances taking into consideration tasks, demand, and resources based on real-world data from the pediatric ED at a large university hospital.

\section{An activity-based method for modeling pediatric ED}

A case study has been developed from a prestigious ED in Sweden. Swedish hospitals prioritize patient-centered care. Governance in Swedish healthcare aims to create functional healthcare systems that operate effectively as part of the social welfare services [32]. Scholars are mainly focusing on lean-inspired production to improve efficiency or mean-inspired production to positively influence the work environment [33], but still, in such high settings combined with a patient-centered care production philosophy, the strategic engineering of resilient organizations rarely focuses on a combined view where care process improvement is discussed alongside its consequences on the employees' work conditions (how many tasks an employee needs to perform and the occupancy of human resources in working hours). It is believed that the enterprise simulation level of serious game application could support changing the strategies. However, there are a lack of guidelines and simulation gaming solutions to support the above stated goal.

The workflow of the pediatric ED was divided into patient admission, triage, waiting time for examination by a physician, examination and patient discharge from the ED. Initial triage refers approximately $40 \%$ of all patients daily to the intermediate healthcare facilities since their issues are less than urgent. After triage, patients will be sent to care modules and be seen based on the urgency and severity of the case. A care module is a basic production unit of an ED where infrastructure and interprofessional teams are provided. In the simulation, the red modules are for resuscitation and critical patients, whereas the orange, yellow, green, and blue modules are for less critically ill patients. The modules are located in separate parts of the ED. The details of the involved healthcare professionals in general and in the studied ED in particular are reported in Sections 3.2 and 4.1 , respectively.

\subsection{Alleviation of overcrowding}

The triage coding system adopted in the real system implemented at Karolinska is based on the Manchester Triage System (MTS) and uses a five-level scale classification, as is implemented in many emergency care systems in Germany, Sweden, Norway, the Netherlands, Austria and other countries [34]. Breaking down the flows into the input, throughput, and output of patients allows an easier view for observing the sources of overcrowding and what can be improved in each building block. Each patient is assessed by a triage nurse and assigned clinical priority. From an operational perspective, the triage category must be determined in the clinic because it will influence the corresponding resource management strategy of the patients. If the orange module is subject to high demand, the next patient might be directed to the waiting space before being treated in the ward. The alleviation of crowding can be separated into input, throughput and output 
blocks (see Figure 2). This is the observed data upon which the model is based. The throughput part is the most common place where a preventable access block for getting timely emergency medicine is generated by having too many low-severity patients.

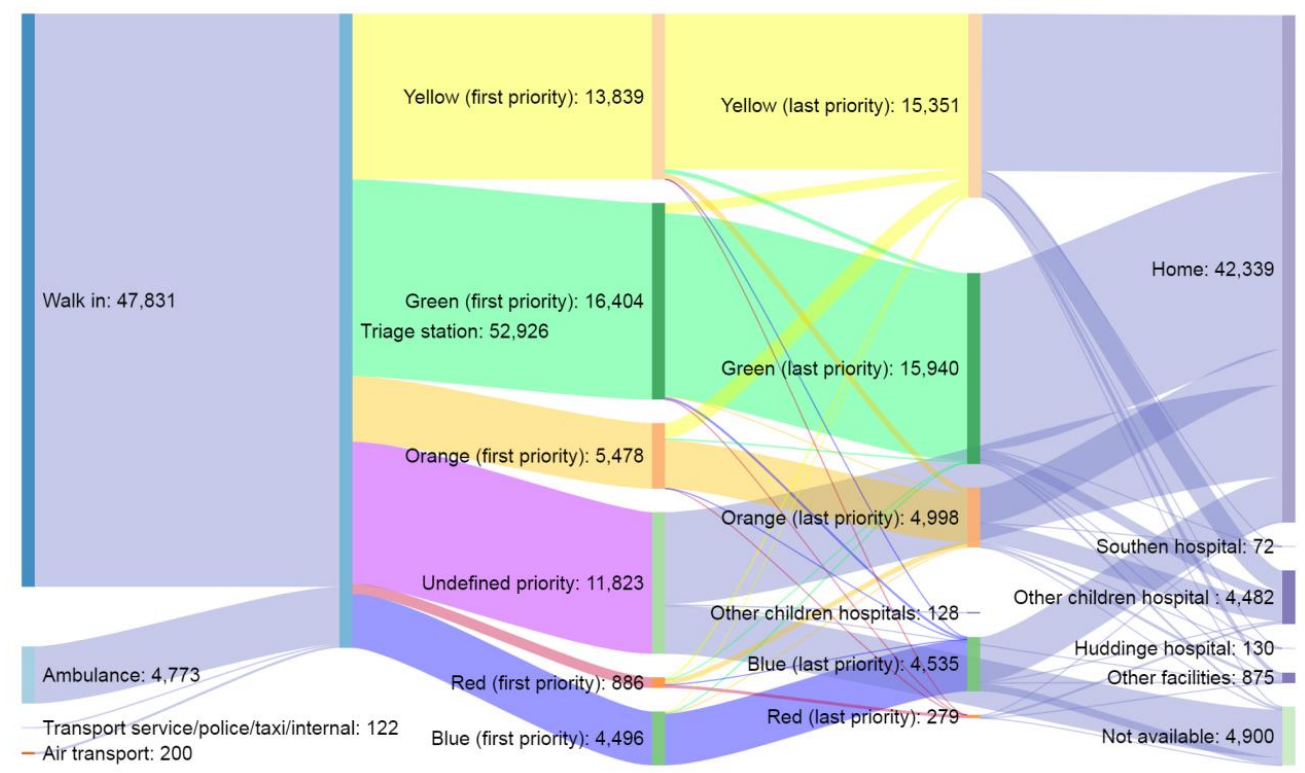

Figure 2. Solution procedure of modeling, simulation and experiment processes for circumventing logistics management problems in ED

\subsection{Tasks for doctors and nurses}

To facilitate the association of medical tasks and the gaming/simulation building blocks, it is easier to use a standardized process modeling language to construct the framework. Business Process Modelling Notation (BPMN) was chosen because it has been relied upon for understanding value streams in complex patient pathways [35], especially with actors involved. This formalism is considered to be the most suitable and widely understandable language for representing a logistics system [36], provisionally governed by the theory of constraints in operational sciences. A guideline was developed, adapted and inspired by Classe et al., where a playable business model was created that guided the easy development of digital games [37]. The meanings of the BPMN elements used are in Table 2.

\subsection{Empirical data}

We use authentic scheduling plans for doctors and nurses, as presented in Table 3. Personnel are organized into three shifts: morning, day and night. Based on a need-based and flexible operation strategy, the emergency room in the red module and those in the orange and yellow modules are not manned by employees. Instead, the emergency rooms will summon resources from the normal modules when an emergency team is needed or when they receive a child in need of resuscitation. Normal modules are the blue and green modules, as well as the triage station. It can be seen from the shift plan that the handoff time is scheduled between the first and second shift. There are two day shifts, which start at 7:00 AM and 1:00 PM, and one night shift, which starts at 9:00 PM.

The length of time needed to complete different tasks was decided by an experienced emergency physician based on real data on the amount of time needed to perform different tasks. Depending on the nature of the task, the task time is spread evenly between intervals or is subject to a maximum length, as documented in Table 4 and 5. A wide variety of 60 different tasks were identified for more than 16 different patient streams in the ED. The time and human resource requirement varied to a large extent. For transport management or likely administration-type tasks, only a few minutes require the 
Table 2. A transverse mapping guideline between the process model elements and the gaming simulation building blocks.

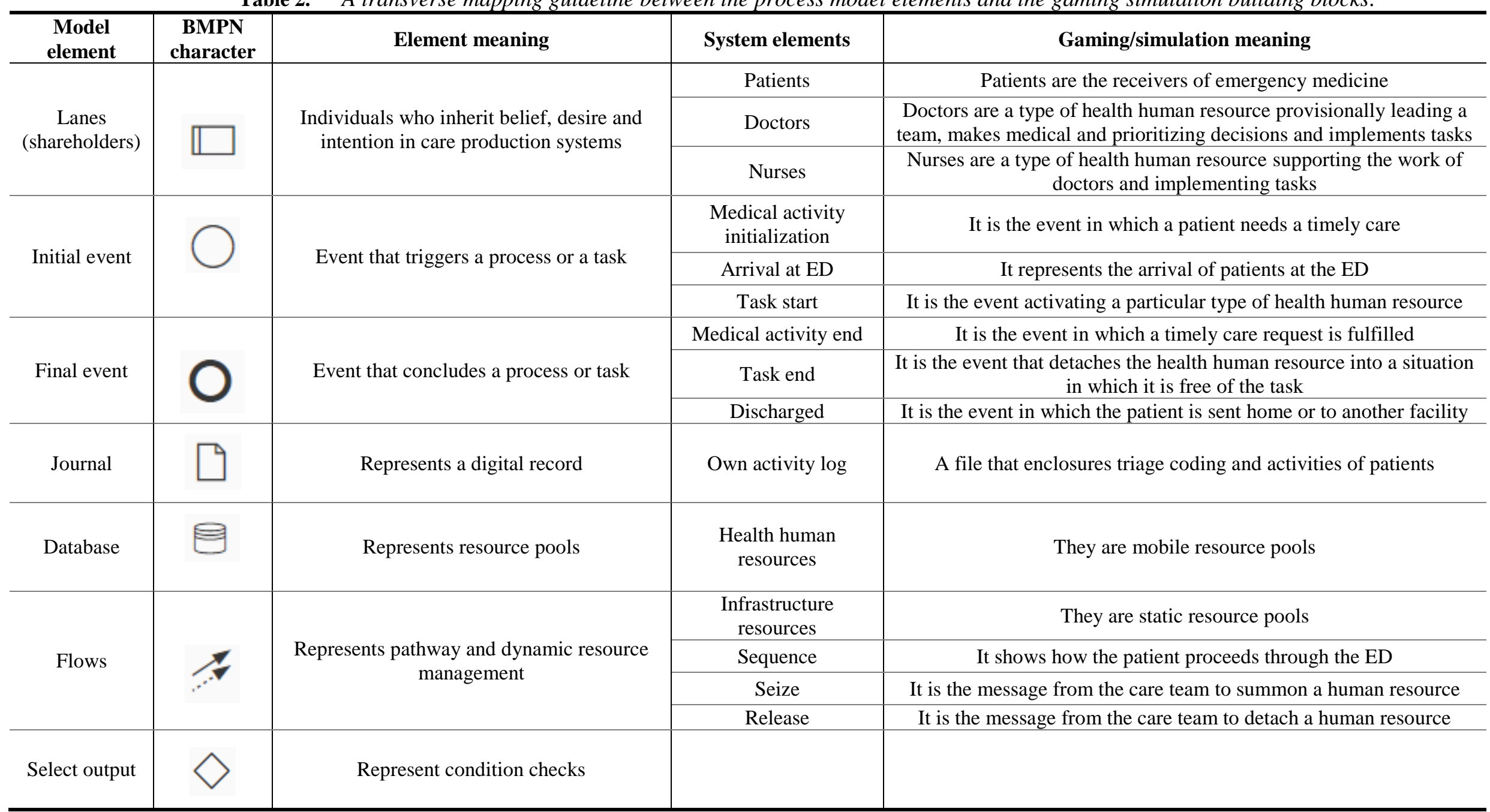


Table 3. Shift plans for doctors and nurses.

\begin{tabular}{|c|c|c|c|c|c|}
\hline \multicolumn{2}{|c|}{ Shift 1} & \multicolumn{2}{|l|}{ Shift 2} & \multicolumn{2}{|c|}{ Shift 3} \\
\hline HR for Triage & Time & HR for Triage & Time & HR for Triage & Time \\
\hline nurse1/Larm & $7-15: 30$ & nurse1 & $13-21: 30$ & nurse1 & 21-07:15 \\
\hline nurse2/Larm & $7-15: 30$ & nurse2/Larm & $13-21: 30$ & nurse2/Larm & 21-07:15 \\
\hline nurse 3 & $7-15: 30$ & nurse 3 & $13-21: 30$ & & \\
\hline nurse4 & $7-15: 30$ & nurse4 & $13-21: 30$ & & \\
\hline HR for Blue module & Time & HR for Blue module & Time & HR for Blue module & Time \\
\hline nurse1/Larm & $7-15: 30$ & nurse1/Larm & $13-21: 30$ & nurse1/Larm & 21-07:15 \\
\hline nurse 2 & $7-15: 30$ & nurse2 & $13-21: 30$ & nurse2 & 21-07:15 \\
\hline nurse 3 & $7-15: 30$ & nurse3 & $13-21: 30$ & nurse3 & 21-07:15 \\
\hline doctor1/Larm & $7: 30-15: 30$ & doctor1/Larm & $15-23: 00$ & doctor1/Larm & 21-08:30 \\
\hline doctor 2 & $7: 30-16: 00$ & doctor 2 & $13-21: 30$ & doctor2 & $20: 30-08$ \\
\hline HR for Green module & Time & HR for Green module & Time & HR for Green module & Time \\
\hline nurse1/Larm & $7-15: 30$ & nurse1 & $15-23: 00$ & nurse1/Larm & 21-07:15 \\
\hline nurse2/Larm & $7-15: 30$ & nurse 2 & $15-23: 00$ & nurse2 & 21-07:15 \\
\hline doctor 1 & 07:30-16:00 & nurse3 & $13-21: 30$ & doctor1/Larm & 21-08:30 \\
\hline doctor2 & & doctor1/Larm & $15-23: 00$ & doctor2 & 17-02:00 \\
\hline & & doctor $2 \rightarrow$ & $17-02: 00$ & & \\
\hline HR for Red module & Time & HR for Orange module & Time & HR for Orange module & Time \\
\hline & & nurse1 & $10-18: 30$ & & \\
\hline & & nurse2 & $10-18: 30$ & & \\
\hline & & doctor1 & 10-18:00 & & \\
\hline & & doctor2 & 10-18:00 & & \\
\hline
\end{tabular}


Table 4. Time and resource requirements of nurses only from pediatric emergency care nursing tasks.

\begin{tabular}{|c|c|c|c|}
\hline Task & Human resource required & $\begin{array}{c}\text { Time needed } \\
\text { (for task, same below) }\end{array}$ & Note \\
\hline Vital parameters & 1 nurse & 3 minutes & \\
\hline Handling of urine samples & 1 nurse & 3 minutes & \\
\hline Transport management & 1 nurse & 5 minutes & \\
\hline Capillary blood sample & 1 nurse & 5 minutes -2 hours & \\
\hline Bladder scan & 1 nurse & 5 minutes & \\
\hline RB CRP & 1 nurse & 10 minutes & \\
\hline Blood test reply & 1 nurse & 10 minutes -2 hours & \\
\hline Blood exam & $1-2$ nurses & 10 minutes - 2 hours & 5 minutes if the priority code is red \\
\hline Medicine effect & 1 nurse & 5 minutes - 1 hour & \\
\hline Body temperature measuring & 1 nurse & 5 - 10 minutes & \\
\hline Control urinary discharge & 1 nurse & 5 minutes - 1 hour & \\
\hline Finished at emergency department & 1 nurse & 5 - 10 minutes & \\
\hline Capillary blood gas department received & 1 nurse & 5 - 20 minutes & \\
\hline Inhalation therapy & 1 nurse & 10 minutes & \\
\hline Identity band & 1 nurse & 5 minutes & \\
\hline Provide medicine & 1 nurse & 5 - 20 minutes & \\
\hline F hemoglobin sampling & 1 nurse & 15 minutes & \\
\hline EMLA application & 1 nurse & 1-5 minutes & \\
\hline EKG & 1 nurse & 5 - 10 minutes & \\
\hline Blood gas exam & 1 nurse & $5-10$ minutes & \\
\hline B-CRP & 1 nurse & 10 - 30 minutes & \\
\hline Wound care/ applying cast to fracture & 1 nurse & 30 - 45 minutes & \\
\hline
\end{tabular}


Table 5. Time and resource requirements with involvement of doctors and technical supports from pediatric emergency care nursing tasks.

\begin{tabular}{|c|c|c|c|}
\hline Task & Human resource required & Time needed & Note \\
\hline Urine collection & Parents or 1 staff member & 15 minutes - 3 hours & Prioritized \\
\hline Telephone contact & 1 nurse or 1 secretary or 1 doctor & $5-30$ minutes & Prioritized \\
\hline Wound cultivation & 1 nurse or 1 doctor & $5-15$ minutes & Prioritized \\
\hline Strep A test & 1 nurse or 1 doctor & 20 minutes & Prioritized \\
\hline Radiology exam & Patient or 1 nurse (X-ray department) & 15 minutes - 1 hour & \\
\hline Radiology test reply & 1 radiologist or 1 doctor & 15 minutes - 2 hours & \\
\hline Radiology preparation & 1 doctor or 1 nurse & $5-10$ minutes & \\
\hline Re-evaluation & Whole team or 1 doctor or 1 nurse & 5 minutes & Prioritized \\
\hline Intravenous line in & Whole team or 1 nurse & 10 minutes - 7 hours & If a scared child, need 2 or 3 staff \\
\hline Operation planning & 1 surgeon & 10 - 20 minutes & \\
\hline Doctor in & 1 doctor & 10 minutes - 1 hour & \\
\hline Lung radiology exam & Patient or 1 nurse (X-ray department) & $20-40$ minutes & Installing devices needs one more nurse \\
\hline Lumbar puncture & 1 doctor and nurse (1-2) & 15 minutes - 1 hour & \\
\hline Order a consultation & 1 doctor & 5 minutes - 2 hours & \\
\hline Decision of admission to ward & 1 doctor & 5 minutes - 1 hour & Sometimes a second hour before decision \\
\hline Provide fluid replacement & Parents or 1 doctor & $1-4$ hours & \\
\hline EEG routine & 1 doctor/staff from neurophysiology department & 2 hours & \\
\hline Blood pressure measurement & 1 nurse or 1 doctor & 10 minutes & \\
\hline Return of lab results & Lab & 10 minutes - 2 hours & \\
\hline Child observation & 1 nurse and 1 doctor & $1-6$ hours & \\
\hline Larm & Whole team & 10 minutes - 1 hour & In emergency rooms \\
\hline
\end{tabular}


pag. 58

involvement of a nurse. For tasks such as taking off bandages, the minimum time required is 30 minutes. More importantly, many tasks might last from a few minutes to almost one hour. Among all tasks, urine collection, telephone contact, wound cultivation, Strep A tests, and re-evaluation are the most commonly performed tasks. All in all, these phenomena demand dynamic resource management strategies of the work system that are sufficiently efficient and available in a timely manner. For the attainment of management indications, the simulation modeling with a few counters and a limited number of patient entries, as shown in the literature review are no longer suitable, considering the complexity of patients, which points to the need for an activity-based approach if the patient flows through the ED are to be modeled or simulated accurately enough to be meaningful for strategic proposals.

\section{Serious game design}

\subsection{Process-simulation mapping document}

This section presents our proposal of process-simulation mapping documents. The motivation is to show the business intelligence of an ED that has been neglected in previous studies. Based on meetings with experts, broad empirical data, and observational efforts on the work system mechanisms of the pediatric ED, the main contribution was determined to be guiding the simulator and game designer through activity-based building blocks in an understandable process language. Without such a comprehensive approach to the flows, simplified flowcharts used in many discrete-event simulations can easily be violated by reality.

Activities of actors in ED are presented in Figure 3. The actors are modelled as three agents: patient, doctor and nurse. The whole process starts with the arrival of the patient at the ED, where a decision has to be made about acceptance. The rejected patients are discharged. Each admitted patient seizes a diagnose room and a nurse in the triage phase. After being tagged with a priority code, the patient releases the triage resources. In accordance with the priority code of the patient, the management nurse appoints a module room and required human resources for the primary diagnose. The patient proceeds to the medical activity accomplishment block, a procedure that is iterated until there are no remaining tasks. The human resource and time needed are manifested in the activity log for each task in order to realize the constraints of care production.

An important issue during this serious game design is to transform the complex processes and work system details into a challenging game. The implications of participatory decision making are examined in this study based on a simulation model of a massive number of artificial entities that could respond to changes in the environment of the ED. To tackle this issue, in the design process, an integrated simulation approach is adopted by the discrete-event simulation and agent-based modelling of entities. Although these simulation approaches tackle the process-based production system in the ED together and the individual characteristics of its actors, the system performance also relies on player decision making. The next paragraph presents strategies used for this transformation issue.

\subsection{Strategies adopted for translating complex healthcare processes into a serous game}

The design and development of serious games on the topic of resource management requires the engine to respect operational constraints, to enable the calculation of utilization values at both aggregated and individual levels, and to be capable of situating a large amount of pseudo-agents in a process-oriented environment as well as animating them at runtime. To accomplish these challenges, AnyLogic (8.4.0, AnyLogic Company, 


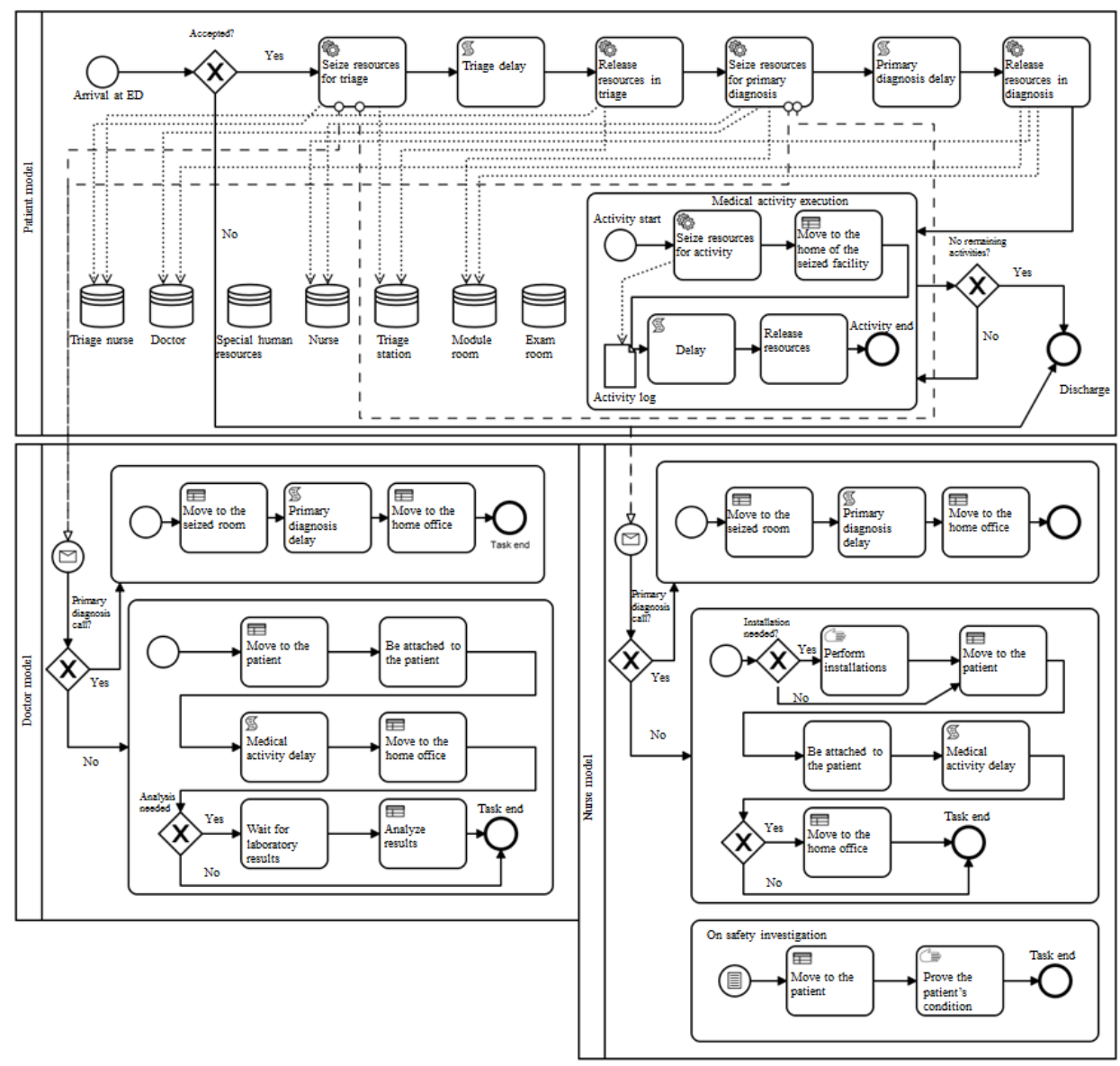

Figure 3. The ED production system represented by actors of patients, doctors and nurses

North America), an integrated simulation and modeling environment [38], was selected for simulation implementation. This is because the software's processing library functionally matches BPMN elements, thus allowing the complete representation of an industrial value chain. The integrated development environment provides the system architecture, see [39].

\subsubsection{Discrete-event simulation}

The discrete-event simulation designed in this study initiates patient attributes on individual care pathways from a realistic modelling of the ED production system. The upstream and downstream medical activities that would potentially be executed for a patient are preconditioned. During the simulation, a selection process is conducted by using the corresponding building block in the software's process library to perform the triage process. This building block randomly assigns a code based on its weight for all feasible options in 2017 operation year. Thereafter, the code might change after the primary diagnosis for the same patient, possibly demanding a different time interval for a nurse-mandated safety investigation.

The modules, exam rooms and human resources of the ED are represented as resource pools. They are presumed to be in ideal working situation, meaning that there would be efficient coordination for seizing a resource pool and transparent information with regard to their availabilities. The number of resource units that are needed for an individual patient is determined as shown in Table 4 and 5. The patient care pathway is decomposed into triage, primary diagnosis and all medical activities. An iterative procedure is conducted until there is no remaining medical activity. The discrete-event simulation model is the environment for agents. 
pag. 60

\subsubsection{Agent-based model}

The agent-based model in the serious game simulates the responses of patients and human resources as well as their progress in the discrete-event simulation. The asynchronous representations of individuals are built into their states. The time delays are decided by the interactions between agents and the environment, including waiting, seizing, being treated or providing service, and releasing. The time horizon of being treated or providing service is determined using a triangular distribution with boundaries and the mean value for each activity; however, the lead time and patient length of stay are computed as aggregators of individual activities. The availability of agents depends on whether they have been assigned tasks. The types of doctors, nurses and special human resources are modelled with identities and operation rules. The shift plans for human resources are explicitly represented by the schedule.

Patients are generated based on an exponential distribution with the average arrival rate as the parameter. A medical activity log is created for each patient with a sequence of medical activities. To be as realistic as possible, a particular patient activity will only be initiated if its probability distribution returns the true value. During the serious game, each patient would undergo the sequence. When seizing resources, the patient agent will take into consideration the priority code and the availability of the resources. Only the patients who are treated in the red module will initiate an emergency call and absorb resources over the ED. A service delay either in a primary diagnosis or in a medical activity execution would occur before the seized human resources are released. Those immediately relocated resources will return to their previous tasks after the emergency call is finished. The patients are served by a first in, first out queuing discipline. The resource requirements of the prioritized tasks are placed on top of the queue. Resource utilization is the output of the seizing and releasing executions.

\subsubsection{Serious game based on multi-method simulation approaches}

The serious game based on the discrete-event and agent-based simulations is a virtual ED where the player takes the role of an ED management nurse and plans the resource allocations at run time based on the ED status. The ED status is updated and visible through a performance graph based on the interaction among patient inflows, health infrastructure and human resources, as Figure 4 illustrates. The management nurse is expected to allocate human resources in all modules. Human resources are defined to carry out a wide variety of activities. Therefore, it is critical for players to become cognitively familiar with the dynamics of the production system, which will require the player's non-technical skill for effective management of resources. A later chapter explains how the game mechanics are designed in the serious game. 

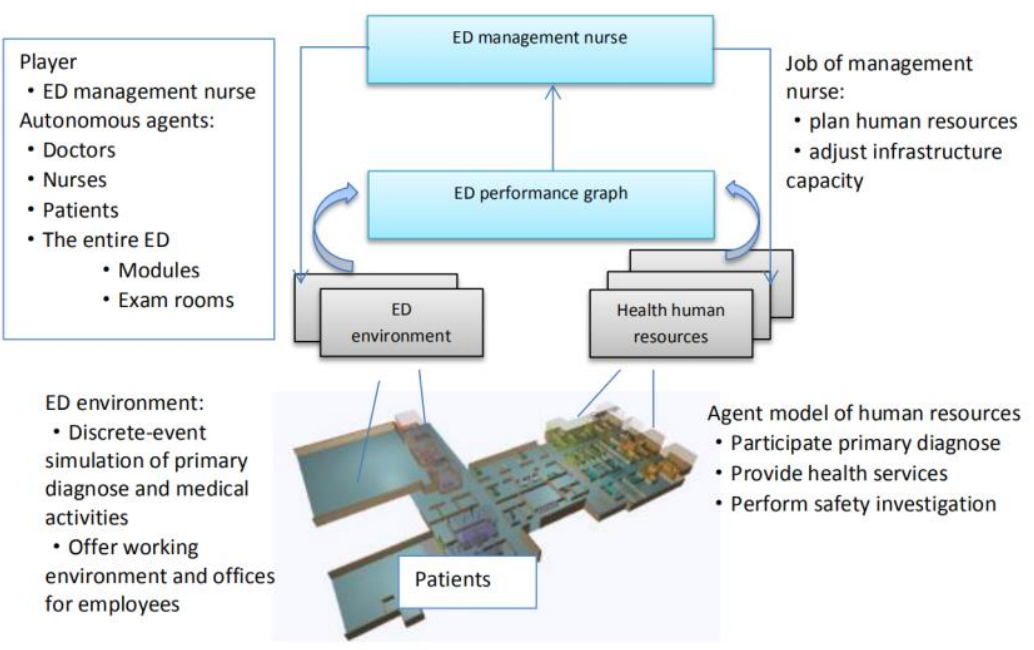

Figure 4. Developing a challenging serious game based on the complexity and business intelligence of the ED production system

\subsubsection{Measurements of logistical performances}

Agent-based modelling offers accessibility for simulated entity state charts. This allows for tracing the events, activities, variables of associated resource types even if the agent needs to go through complex processes. Figure 5 presents how the service is simulated in this study, associated with a simulation log registering all the procedural and temporal information in the database at run time. The procedural and temporal information used for the measurements of logistical performances are represented by the symbols in Table 6 . The measurements of logistical performances are based on a previous work addressing urban resource management problems in which resource utilizations and production times are critical [40].

Table 6. Parameters, variables and indicators and their descriptions

\begin{tabular}{c|c}
\hline \multicolumn{2}{c}{ Indicators } \\
\hline $\mathrm{i}, \mathrm{j}, \mathrm{t}$ & Gaming time stamp \\
\hline $\mathrm{m}$ & An agent-to-carry-out medical acitivty \\
\hline $\mathrm{n}$ & Type of the resource agent \\
\hline $\mathrm{M}$ & Set of all medical activities \\
\hline $\mathrm{C}_{\mathrm{n}, \mathrm{t}}$ & Capacity of the resource agent of type $\mathrm{n}$ at time $\mathrm{t}$ \\
\hline $\mathrm{M}_{\mathrm{n}}$ & Set of all medical activities for the resource agent of type $\mathrm{n}$ \\
\hline $\mathrm{s}$ & Module section of the emergency department \\
\hline$\prod_{\mathrm{m}, \mathrm{n}}^{+}$ & Variables regarding temporal information \\
\hline$\prod_{\mathrm{m}, \mathrm{n}}^{-}$ & Time of m's seizing of a resource agent of type $\mathrm{n}$ \\
\hline$\delta_{\mathrm{m}, \mathrm{n}}^{+}$ & Time of m's releasing of a resource agent of type $\mathrm{n}$ \\
\hline$\delta_{\mathrm{m}, \mathrm{n}}^{-}$ & Time of m's arrival requesting a resource agent of type $\mathrm{n}$ \\
\hline
\end{tabular}

$b_{m, n}^{+}[i, j]$ and $b_{m, n}^{-}[i, j]$ are binary variables for the indication of the task m's presence in the investigated operating time horizon:

$$
\mathrm{b}_{\mathrm{m}, \mathrm{n}}^{+}[\mathrm{i}, \mathrm{j}]= \begin{cases}1, & \text { if } \mathrm{i}<\prod_{\mathrm{m}, \mathrm{n}}^{+}<\mathrm{j} \\ 0, & \text { if } \prod_{\mathrm{m}, \mathrm{n}}^{+} \leq \mathrm{i} \text { or } \prod_{\mathrm{m}, \mathrm{n}}^{+} \geq j\end{cases}
$$


pag. 62

$$
\mathrm{b}_{\mathrm{m}, \mathrm{n}}^{-}[\mathrm{i}, \mathrm{j}]= \begin{cases}1, & \text { if } \mathrm{i}<\prod_{\mathrm{m}, \mathrm{n}}^{-}<\mathrm{j} \\ 0, & \text { if } \prod_{\mathrm{m}, \mathrm{n}}^{-} \leq \mathrm{i} \text { or } \prod_{\mathrm{m}, \mathrm{n}}^{-} \geq j\end{cases}
$$

$\widehat{\mathrm{w}}_{\mathrm{n}, \mathrm{t}}$ is the workload for a particular agent type updated throughout the game. It is computed by subtracting the sum of the finished task count from the sum of the incoming tasks that successfully seize the resource agent:

$$
\widehat{w}_{n, t}=\sum_{m \in M_{n}} b_{m, n}^{+}[0, t]-\sum_{m \in M_{n}} b_{m, n}^{-}[0, t]
$$

$\mathrm{u}_{\mathrm{n}, \mathrm{t}}(\mathrm{s})$ is the resource utilization value reflecting the fraction of time during which the resource agent is occupied. It is an important proportion-based measurement for reflecting the availability of a resource pool. Given the workload and the capacity of the resource pool, the resource utilization is computed as:

$$
\mathrm{u}_{\mathrm{n}, \mathrm{t}}(\mathrm{s})=\frac{\widehat{\mathrm{w}}_{\mathrm{n}, \mathrm{t}}}{\mathrm{C}_{\mathrm{n}, \mathrm{t}}}
$$

$\overline{\mathrm{u}_{\mathrm{n}}(\mathrm{s} \mid \mathrm{l}, \mathrm{\jmath})}$ is the average utilization is computed as the mean over all individual utilizations in the investigated time horizon.

$$
\overline{\mathrm{u}_{\mathrm{n}}(\mathrm{s} \mid \mathrm{l}, \mathrm{j})}=\sum_{\mathrm{t} \in[\mathrm{i}, \mathrm{j}]} \frac{\widehat{\mathrm{w}}_{\mathrm{n}, \mathrm{t}}}{\mathrm{C}_{\mathrm{n}, \mathrm{t}}} /\left(\prod_{\mathrm{m}, \mathrm{n}}^{-}-\prod_{\mathrm{m}, \mathrm{n}}^{+}\right)
$$

$\overline{\operatorname{lt}_{\mathrm{n}}(\mathrm{l}, \mathrm{J})}$ is the institutional average lead time of seeing a doctor. Here, the medical activity only refers to the primary diagnosis.

$$
\overline{\mathrm{tt}_{\mathrm{n}}(\mathrm{l}, \mathrm{j})}=\sum_{\mathrm{t} \in[\mathrm{i}, \mathrm{j}]} \frac{\delta_{\mathrm{m}, \mathrm{n}}^{-}-\delta_{\mathrm{m}, \mathrm{n}}^{+}}{\sum_{\mathrm{m} \in \mathrm{M}_{\mathrm{n}}} \mathrm{b}_{\mathrm{m}, \mathrm{n}}^{-}[0, \mathrm{t}]}
$$

$\overline{\operatorname{los}(1, \mathrm{~J})}$ is the institutional average length of stay. The entire hospital visit is regarded as the medical activity with the emergency department as the resource agent.
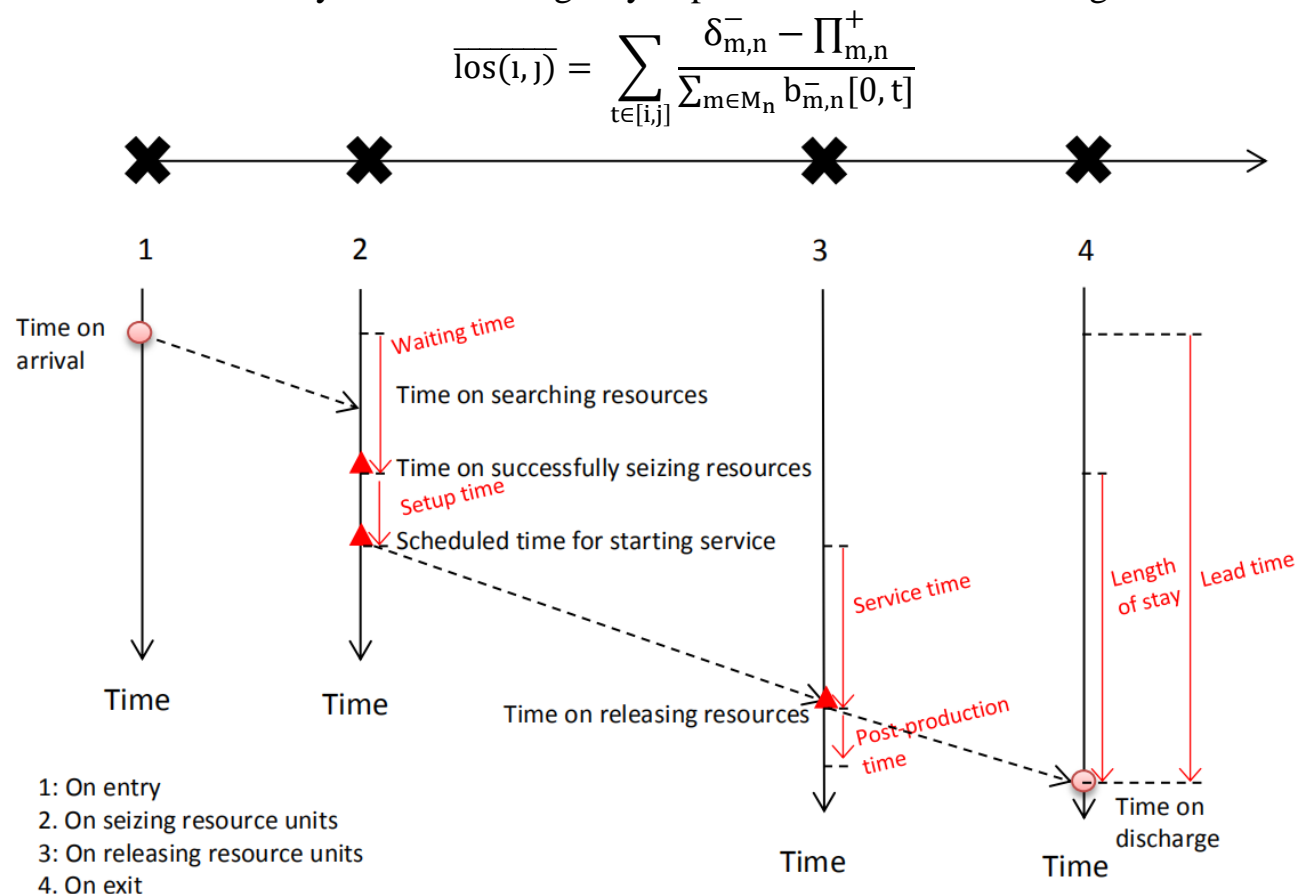

Figure 5. Health service provision model in an ED

\subsection{Game mechanics}

The selection of game mechanics has been suggested by many previous works, and here, we refer to the LM-GM map [41]. The process in which analytical skills are practised 
involves many important learning mechanics. Given the third aim of this study, it is clear that players of the game are expected to be in a responsive position, fostering the performance of the ED system in the processes of planning, observing the complexity of the system and reflecting on the relationship between resource configurations and the quality of care. The task is challenging given that the player needs to balance a large number of patients and resource units. According to the self-determination theory by Deci and Ryan, human beings are motivated to deliver if they encounter feelings of being competent in dealing with a situation or task and if they are free to make their own choices [42]. The management can only be successful if the player compares a number of feasible decision-making alternatives based on the indicators of the ED performance and develops a better understanding of the system.

The game mechanic of status is selected to encounter responsibility. In this study, the status considers the quality of care indicators that are officially part of the hospital enterprise resource planning tool used by the real ED manager on a daily basis. These indicators include resource utilization for doctors, nurses, special human resources and patient length of stay. They are shown on average. This is because, similarly, the calculation of such indicators is often estimated using the average method in simulation studies of ED management issues [43][44][45]. As presented in Figure 6, in the scenario manager, the player can access the systematic status through the tab "stats". There are three blocks. The utilization of resources is updated according to its measurement methodology in the previous section. The graphs on the weekly pattern of arrival rate and a comparison of simulation results with historical data are for validation purposes. Here, the player can overview incoming patient flows for the entire game session and compare them with historical data. The histograms present the average lead time and patient length of stay since the instantiation of the simulation, in which the red lines indicate the average values for the datasets.

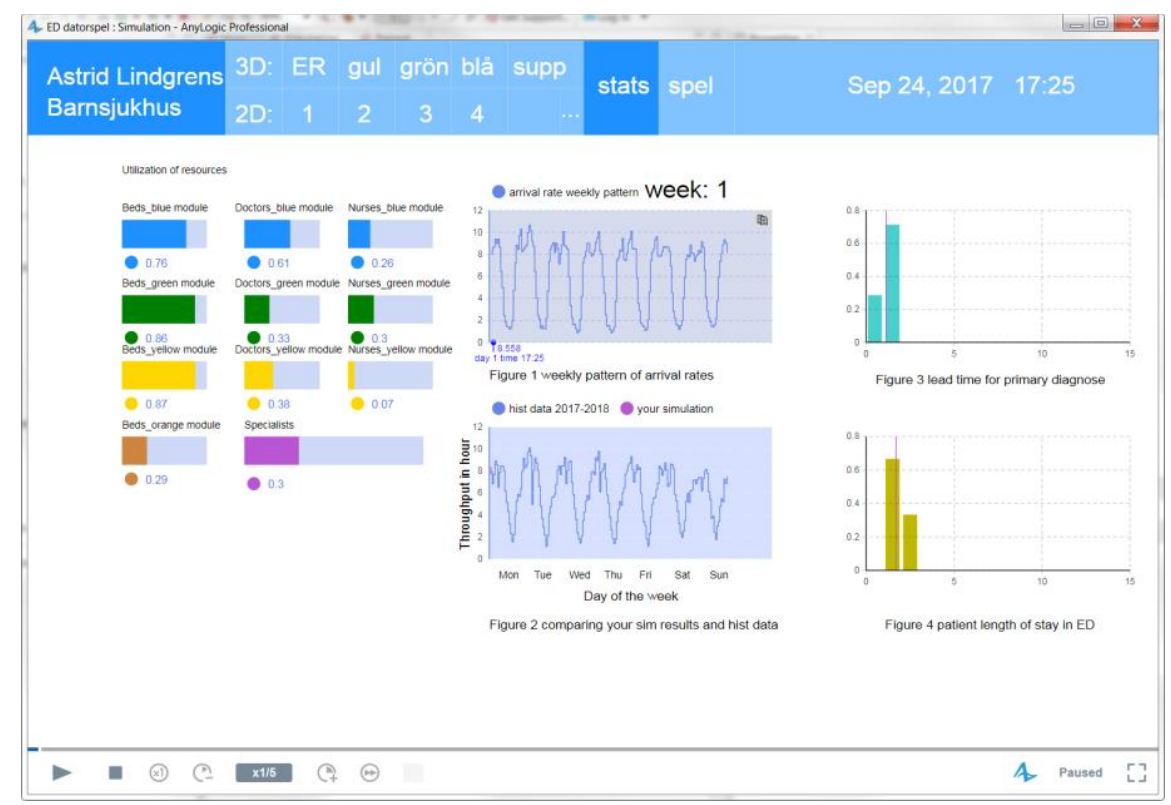

Figure 6. Interface design as an enabler of the status mechanic

The game mechanic of selecting/production choices is selected to support reflection. This is strongly in line with a real production system, as the management work has options to choose based on the various compositions of patient flow and resource characteristics. Although the healthcare capacities are sufficient to accommodate the patient inflow at the start of the operating hours, ED overcrowding is potentially the result of increased inflow during the busy hours of the day. Long queues could occur from the imbalance between patient inflow surges and system responses. The selection/production choices with regards to the configuration of human resources and infrastructure are 
pag. 64

therefore enabled, manifested in the player's actions in the game. The choices first eliminate the irrelevant option for the crew size increments for the entire ED, inclusive of all the scenarios that could be considered by the management nurse.

As presented in Figure 7, players make selections through the sliders under each resource pool. The player's decision making is based on the ED performance but takes effect in the following operation time horizons. Since the profile of each patient is unique, this means that the patients will have various resource demands, requesting the player as the management nurse to make productive choices. The game does not impose restrictions on how many human resources a player shall assign for the modules. However, if the player does not react to patients' requirements with sufficient resources or the human resources are allocated in an inappropriate way, overcrowding and a lack of human resource availability will increase.

The game mechanics of urgent optimism and feedback are selected to encounter motivation and observation, respectively. As Figure 7 presents, the "Feedback" block in the "spel" panel is dedicated to these aims. "Staff availability" and "Bedsides present" are information points for the proportions of available resources in the corresponding resource pools. The resource pools here are beds, doctors and nurses for all modules as well as specialists. The "good" or "not good" indications will be shown if the considered resource utilization is less than $60 \%$ or over $85 \%$, respectively, whilst the "fair" indication takes care of the situations in between. The "Patient happiness" is an information point for the waiting queue length in the reception area. Here, we presume that the patient will be happy about shorter waiting times. This is also the case in reality since emergency department visits expect a faster time to be accepted. According to field studies of the hospital, the normal queue length is 15 individuals when patients are calm, but a queue length longer than 20 individuals will potentially lead to long waiting times. Therefore, the "good" or "not good" indications will be shown if the queue length is less than 15 or over 20, respectively, whilst the "fair" indication takes care of situations in between. To foster urgent optimism, we also include emojis (Windows 10, U+1F60A, U+1F914, $\mathrm{U}+1 \mathrm{~F} 622$ ) following the same rules. In the "Messages for the management nurse" block, the player receives instructions in red on what decision-making options could be adopted.

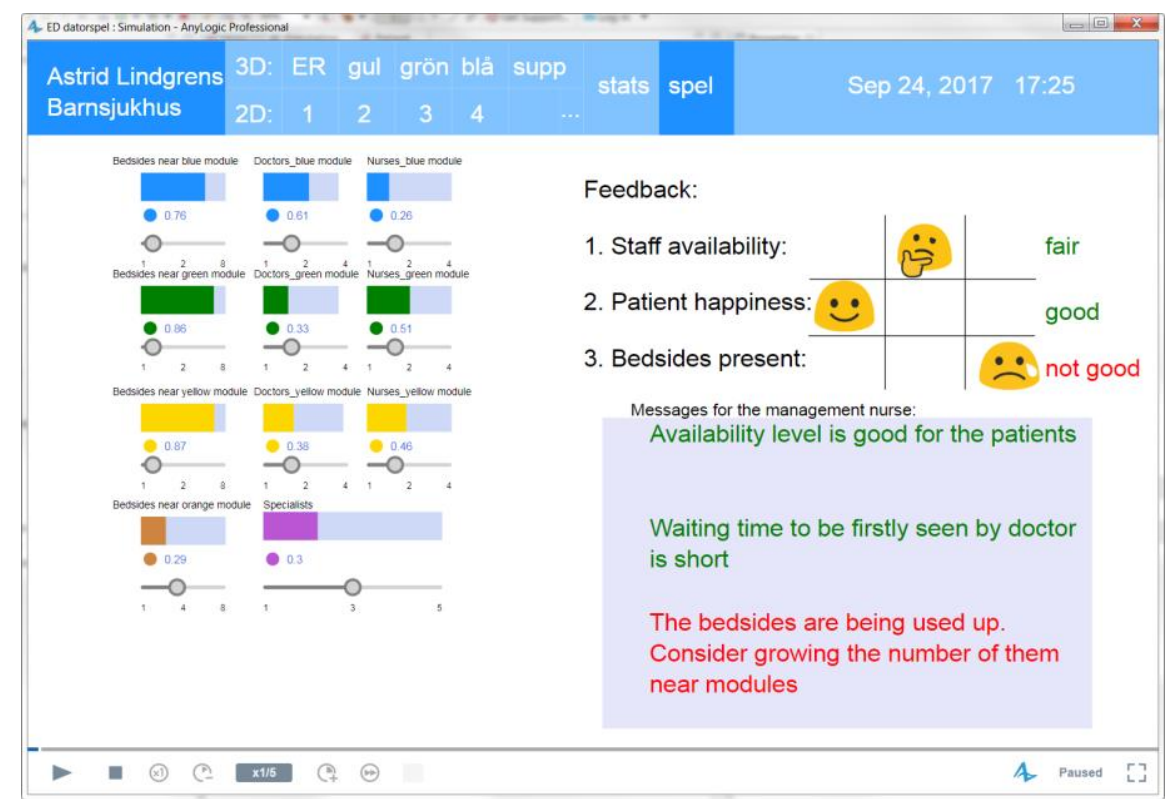

Figure 7. Interface design as an enabler of selection, urgent optimism, and feedback mechanics 


\subsection{Game implementation}

The implementation of the game is a single player-based human computer interaction, as illustrated in Figure 8. The player takes the role as a manager of the ED. The ED managers can navigate every corner of the organization, making changes in the sizes of human resources during the course of the simulated week; however, they cannot administer scenario settings before which the test queries are preconditioned. This means that players must cope with problems residing in access blocks. The outcome of play is expected to imply important knowledge on strategic human resource management in ED.

When the game starts, the player can initiate the simulation with the infrastructure of the ED. The player can explore the ED in the navigation panel. In the beginning phase, the player can only observe the floor plan and human resources. Artificial patients will populate the waiting area of the ED as the ED operating hours start according to the inflow distribution pattern. The patients will be triaged and coded for their priorities, after which the care pathway is implemented with the primary diagnosis and medical activities.

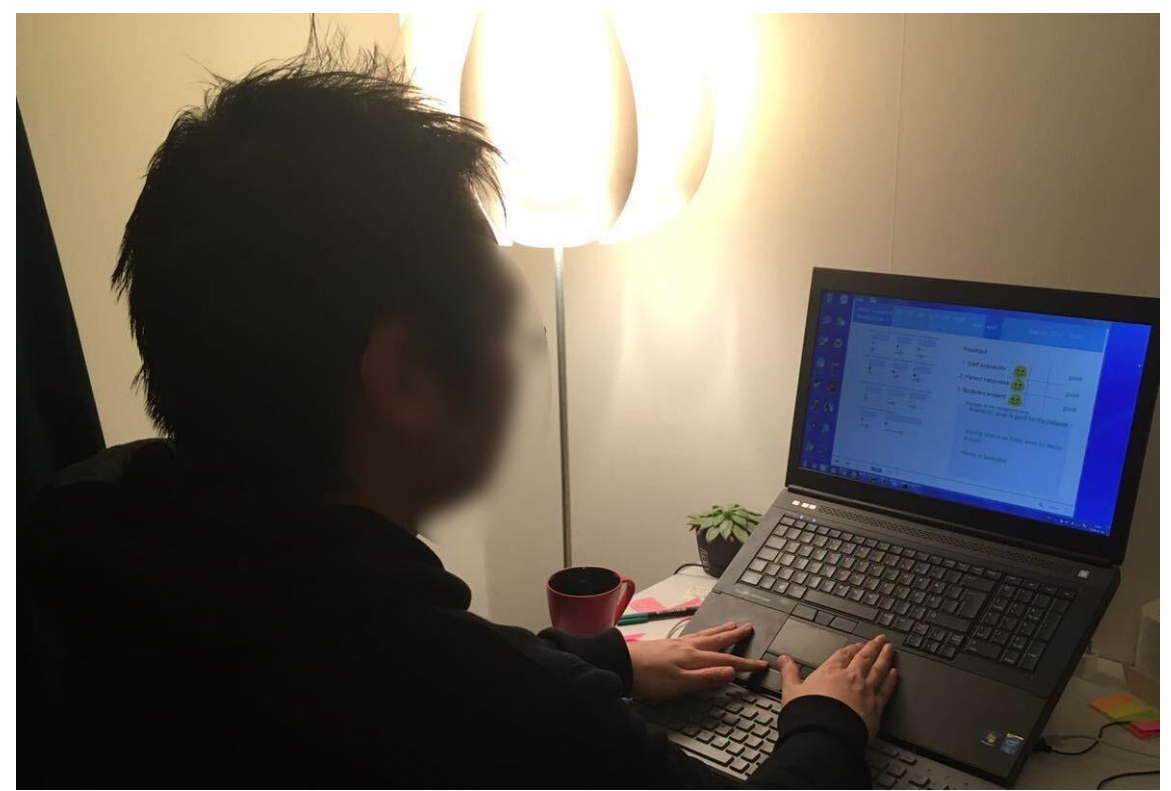

Figure 8. Performing the human resource management by serious gaming

\subsection{Validation}

This study employed internal validation methods. Confidence intervals were used for checking discrete-event simulation validity [46], where the internal check was done by statistics summaries of indicators. Given that the serious game presented in this work has solid discrete-event building blocks that are for processes in care production, a t-test was used for comparing the different indicators. The indicator needed to be on patient flows because the patient flows are usually detrimental to coordination in healthcare logistics and resource management. Therefore, the through number of discharged patients was selected as the indicator. This indicator reflects the accuracy of all heuristics built into the planning tool.

The null hypothesis, which shows no significant difference between the means, was tested at the $\alpha=0.05$ level. The corresponding critical value used for the test was $t$ $(54,0.95) \approx 2.00$. It turns out that no pairs present significant differences with $t$ scores below the threshold, as Table 7 shows. The incoming patient distributions are consistent, as Figure 9 presents.

The simulation is thoroughly visualized to verify the modeling of the working environment mechanism. Earlier studies used discrete-event simulations for learning aims where a visual predictive check is enough for demonstrating the usefulness of the tool 
pag. 66

[47]. In this study, the animation can initially be used for visualizing and communicating the work system to the user. In addition, the animation can be referred to when examining whether the special dimensions are reasonable. The animation is therefore considered to be more complementary than statistical comparisons in the sense that the former facilities communication with the ED personnel who have an overview of the patterns of crew resource movements. In addition, animations are considered equally powerful to other validation techniques [48]. In this serious game, the animations are presented under the tab series "3D" in Figure 7. The player can navigate the ED by clicking on the respective camera scenes. For the reception area and all the modules, mechanical errors do not exist, and the tool has all the structure related to the animation and graphics. In summary, this means that the model apprehends the patient flow properties with sufficient consistency.

Table 7. Comparing simulation results and real data for one year.

\begin{tabular}{c|c|c|c|c}
\hline $\begin{array}{c}\text { Day of the } \\
\text { week }\end{array}$ & $\begin{array}{c}\text { Discharged patients } \\
\text { per day in 2017 }\end{array}$ & $\begin{array}{c}\text { Discharged patients per } \\
\text { day in the planning tool }\end{array}$ & Difference & T-test (n=54) \\
\hline Sunday & 141.13 & 134.25 & -6.88 & 1.46 \\
\hline Monday & 149.46 & 154.25 & 4.79 & -1.64 \\
\hline Tuesday & 140.87 & 136.41 & -4.46 & 1.67 \\
\hline Wednesday & 137.54 & 140.51 & 2.97 & -1.11 \\
\hline Thursday & 137.15 & 133.98 & -3.17 & 1.21 \\
\hline Friday & 139.57 & 136.42 & -3.15 & 1.19 \\
\hline Saturday & 134.39 & 137.54 & 3.15 & -1.20 \\
\hline
\end{tabular}

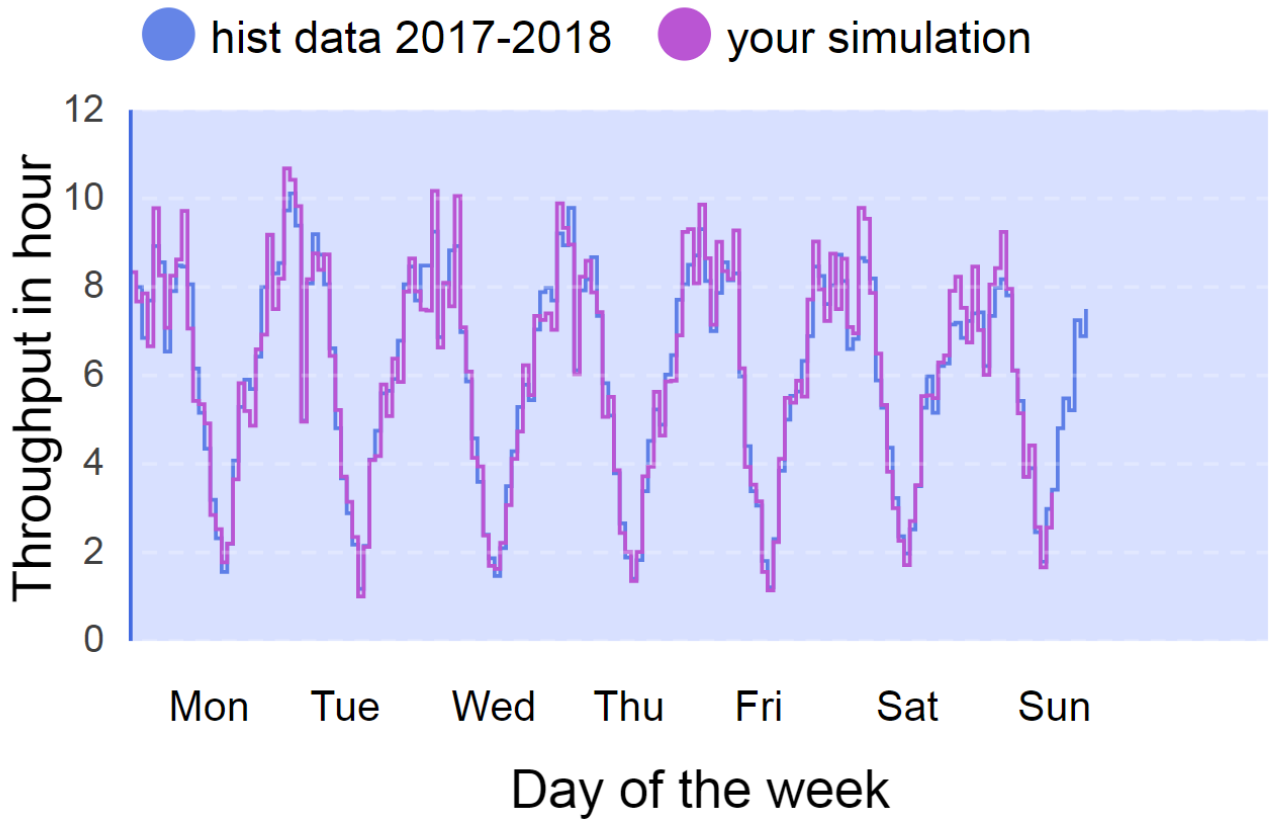

Figure 9. Incoming patients in simulation and in real (blue line: distribution in 2017; red line: distribution in simulation)

\subsection{Experimental methodology and setup}

Observing the baseline scenario and playing test queries were performed with participants from a game-based training workshop [49], in which the debriefing session was selfguided and facilitator-guided combined. In that training exercise, all eighty one participants viewed the simulation of the baseline scenario. The self-guided debriefing session was enabled in follow-up contacts the facilitator established with the participants. 
In follow-up contacts, the interested individuals were given the option in which the serious game embedded with all test queries was played.

For serious game play, this project eventually recruited fifty-one players who joined all test queries. The participants were research students with engineering and management backgrounds. At the time of the experiment, the shares of active undergraduate, master's and $\mathrm{PhD}$ students were $3.9 \%, 58.8 \%$ and $37.3 \%$, respectively. Each player was assigned the role of the ED management nurse. A game session involves operating the ED from Monday until Sunday. The simulation logs are saved in the application folder. After each participant's game session, a suggestion is made to send back the application folder for processing simulation logs.

\subsubsection{Baseline scenario}

Baseline was designed for the aims of performing a simulation-based technological forecasting without intervention from players. This allows for a comparison of prediction outcomes from the two corresponding methods with regard to resource utilization, lead time and patient length of stay. The baseline scenario is exactly the same as the one in validation - see previous section - together with measurements experienced in the real ED (see Table 8). The baseline scenario is only as a reference for both the technological forecasting and the serious gaming experiments.

Table 8. Average resource utilizations, lead time and length of stay in the baseline scenario.

\begin{tabular}{c|c|c|c|c|c}
\hline $\begin{array}{c}\text { Day of } \\
\text { week/measure } \\
\text { ments }\end{array}$ & $\begin{array}{c}\text { Average } \\
\text { utilization } \\
\text { of doctors } \\
\text { in the blue } \\
\text { module }\end{array}$ & $\begin{array}{c}\text { Average } \\
\text { utilization } \\
\text { of nurses in the } \\
\text { blue module }\end{array}$ & $\begin{array}{c}\text { Average } \\
\text { utilization of } \\
\text { special human } \\
\text { resources }\end{array}$ & $\begin{array}{c}\text { Average lead } \\
\text { time (in hours) }\end{array}$ & $\begin{array}{c}\text { Average length } \\
\text { of stay (in } \\
\text { hours) }\end{array}$ \\
\hline Sunday & $53,2 \%$ & $61,2 \%$ & $45,5 \%$ & 2,12 & 3,28 \\
\hline Monday & $57,3 \%$ & $69,0 \%$ & $59,3 \%$ & 1,78 & 3,16 \\
\hline Tuesday & $48,8 \%$ & $50,3 \%$ & $48,4 \%$ & 1,86 & 3,28 \\
\hline Wednesday & $48,4 \%$ & $51,1 \%$ & $43,7 \%$ & 1,81 & 3,24 \\
\hline Thursday & $45,5 \%$ & $56,3 \%$ & $44,5 \%$ & 1,67 & 3,19 \\
\hline Friday & $49,2 \%$ & $54,9 \%$ & $45,9 \%$ & 1,79 & 3,24 \\
\hline Saturday & $41,7 \%$ & $59,5 \%$ & $41,2 \%$ & 1,95 & 3,21 \\
\hline
\end{tabular}

\subsubsection{Operative scenarios}

The operative scenarios that will be performed by the simulation-based prediction and in the serious game are:

- Operative scenario 1: patient inflow is increased by $10 \%$.

- Operative scenario 2: patient inflow is increased by $20 \%$.

- Operative scenario 3: patient inflow is lowered by $10 \%$ and the working hours for doctors and nurses are shortened by $10 \%$.

The operative scenarios are designed based on the consideration of two primary topics in healthcare logistics management pointed out by previous research. The majority of these journal papers investigate the impact of patient flow changes and capacity management [15][50]. Hence, the test queries include two scenarios, namely, patient inflow changes and one scenario that integrates an inflow change and a resource configuration adjustment. The selected magnitudes of changes are valid numbers used for evaluating healthcare system performance in previous simulation studies [16][51], and the player cannot change the conditions of test queries.

The study was conducted in accordance with the Declaration of Helsinki [52] and was a safety-focused evaluation of ED flows and work systems. Since the focus was on the 
pag. 68

flow data, the individual patients were not identifiable by any individual or any party. The study was waived from review by regional ethics committees.

\section{Results}

The average action level during the test queries for changing resource configurations in each simulated hour of each player's game session is presented in Figure 10. From noon until late night characterizes the most intensive time horizon of player inputs via the sliders, particularly on working days from 12:00 onward. On weekend days, this pattern is not significant, but the actions are distributed evenly throughout the working hours. The highest average number of actions in a simulated hour is 12 on Monday. As the players proceed in the serious game, the number of actions tends to decrease. Together, these patterns are in line with the distribution of patient inflow, which verifies that our game mechanics encourage players to take more actions needed for patient flows.
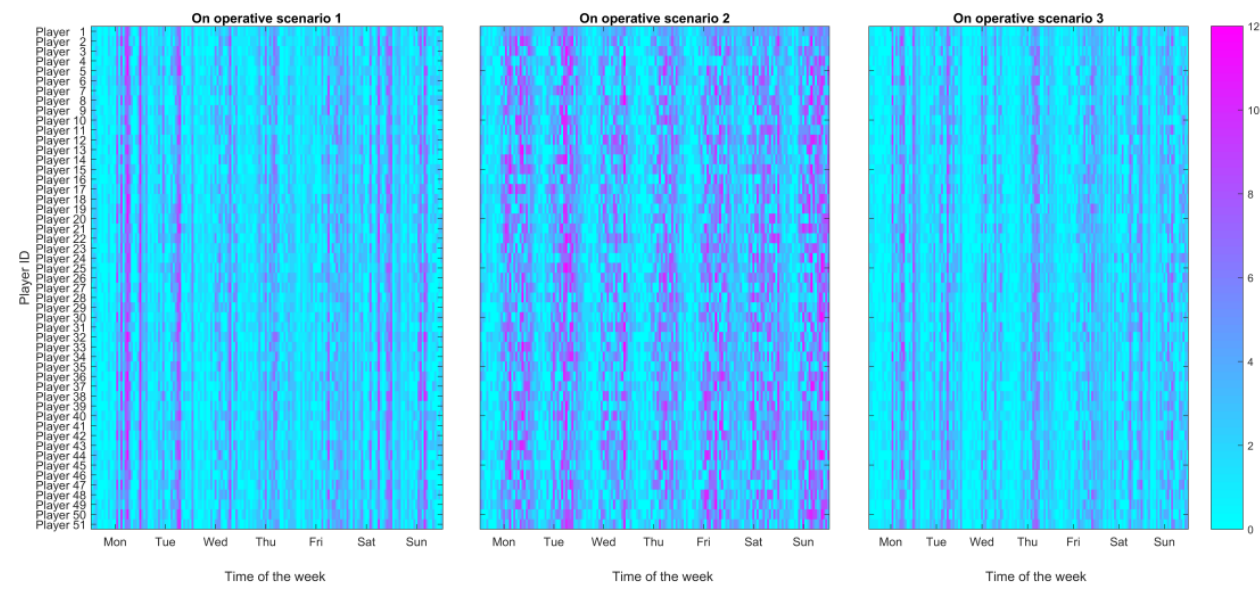

Figure 10. Average frequency of resource adjustment for test queries

The simulation prediction reported that the utilization of doctors would be almost $10 \%$ more as patient inflow increased by $10 \%$ in the first operative scenario. This figure would grow further with another $10 \%$ flow increment - the average utilizations would be higher than $60 \%$. As reported, the average utilization of doctors per weekday in 2017, based on the enterprise resource planning system, varied only between $41 \%$ and $58 \%$. It is worthwhile to note that as long as the patient flow increases $20 \%$ than present, doctors working during Monday shifts is predicted to be occupied more than $80 \%$ of the time (see Table 9). Nevertheless, the pattern is consistent given that the average utilization reaches highest on Sunday and Monday and its lowest on Saturday meanwhile is in line with how inflow fluctuates through the week, with Sunday and Monday having the most incoming patients.

Table 9. Impacts of patient flow and resource characteristics on the average utilization of doctors in the blue module.

\begin{tabular}{c|c|c|c}
\hline Day of week & Operative scenario 1 & Operative scenario 2 & Operative scenario 3 \\
\hline Sunday & $61,2 \%$ & $74,5 \%$ & $54,0 \%$ \\
\hline Monday & $65,9 \%$ & $80,2 \%$ & $58,2 \%$ \\
\hline Tuesday & $56,1 \%$ & $68,3 \%$ & $49,5 \%$ \\
\hline Wednesday & $55,7 \%$ & $67,8 \%$ & $49,1 \%$ \\
\hline Thursday & $52,3 \%$ & $63,7 \%$ & $46,2 \%$ \\
\hline Friday & $56,6 \%$ & $68,9 \%$ & $49,9 \%$ \\
\hline Saturday & $48,0 \%$ & $58,4 \%$ & $42,3 \%$ \\
\hline
\end{tabular}


Using the nurse utilization statistics for 2017, the simulation can estimate the utilization required of nurses per practice (see Table 10). With a $20 \%$ patient flow accession, the nurse utilization was $97 \%$ for the busiest weekday (Monday). The simulation, therefore, suggests that nurses are in a more vulnerable position facing incoming changes in flow compared to doctors. With shorter working hours and a decrease in patient flow, the simulation reported that the human resources of all types would not drastically experience a utilization change themselves.

Table 10. Impacts of the patient flow and resource characteristics on the average utilization of nurses in the blue module.

\begin{tabular}{c|c|c|c}
\hline Day of week & Operative scenario 1 & Operative scenario 2 & Operative scenario 3 \\
\hline Sunday & $70,4 \%$ & $85,7 \%$ & $62,1 \%$ \\
\hline Monday & $79,4 \%$ & $96,6 \%$ & $70,0 \%$ \\
\hline Tuesday & $57,8 \%$ & $70,4 \%$ & $51,1 \%$ \\
\hline Wednesday & $58,8 \%$ & $71,5 \%$ & $51,9 \%$ \\
\hline Thursday & $64,7 \%$ & $78,8 \%$ & $57,1 \%$ \\
\hline Friday & $63,1 \%$ & $76,9 \%$ & $55,7 \%$ \\
\hline Saturday & $68,4 \%$ & $83,3 \%$ & $60,4 \%$ \\
\hline
\end{tabular}

The simulation projected changes on the waiting time and the overall length of stay as important outcomes from the efficiency perspective. In the absence of enough working hours, the time per patient to visit with the doctor and the length of stay will be increased to almost 2 hours for the majority and more than 3.5 hours for all weekdays, respectively. Table 11 shows the average lead time to see a doctor under the different circumstances. Only in scenarios of patient flow changes is waiting time for first examination by a physician no longer under 2 hours. At a 20\% flow increase, the average length of stay will exceed 4 hours, hence not meeting the 4-hour limit for length of stay after which the patient should be discharged, as presented in Table 12 .

Table 11. Impacts of the patient flow and resource characteristics on the average lead time of seeing a doctor in the ED (in hours).

\begin{tabular}{c|c|c|c}
\hline Day of week & Operative scenario 1 & Operative scenario 2 & Operative scenario 3 \\
\hline Sunday & 2,44 & 2,76 & 2,33 \\
\hline Monday & 2,05 & 2,31 & 1,96 \\
\hline Tuesday & 2,14 & 2,42 & 2,05 \\
\hline Wednesday & 2,08 & 2,35 & 1,99 \\
\hline Thursday & 1,92 & 2,17 & 1,84 \\
\hline Friday & 2,06 & 2,33 & 1,97 \\
\hline Saturday & 2,24 & 2,54 & 2,15 \\
\hline
\end{tabular}


Table 12. Impacts of the patient flow and resource characteristics on the average length of stay in the ED (in hours).

\begin{tabular}{c|c|c|c}
\hline Day of week & Operative scenario 1 & Operative scenario 2 & Operative scenario 3 \\
\hline Sunday & 3,77 & 4,26 & 3,61 \\
\hline Monday & 3,63 & 4,11 & 3,48 \\
\hline Tuesday & 3,77 & 4,26 & 3,61 \\
\hline Wednesday & 3,73 & 4,21 & 3,56 \\
\hline Thursday & 3,67 & 4,15 & 3,51 \\
\hline Friday & 3,73 & 4,21 & 3,56 \\
\hline Saturday & 3,69 & 4,17 & 3,53 \\
\hline
\end{tabular}

While the management process being playable in the serious games, the handling of the logistics issues in the ED can be simulated with human decision making in the loop. This is remarkably different from simulation-based predictions disregarding decision making skills from players. This simulated ED with an actuation of human decision making proceeded to positive changes in utilization of resources in the busiest module and systemic efficiency from a patient-centered angle. As reported in Table 13, the average utilization of doctors per weekday varied between $49 \%$ and $57 \%$. The metric reached its highest on Sunday and Monday. In the first operative scenario, outputs from the serious game reported that the utilization of doctors resided in the interval of $51 \%$ and $61 \%$. This figure still increased with another 10\% flow increment but with a less extent. By the third operative scenario, doctors working during Monday shifts would be occupied for over $70 \%$ of the time.

Table 13. Impacts of serious gaming on the average utilization of doctors in the blue module.

\begin{tabular}{c|c|c|c}
\hline Day of week & Operative scenario 1 & Operative scenario 2 & Operative scenario 3 \\
\hline Sunday & $60,5 \%$ & $68,5 \% *$ & $53,4 \%$ \\
\hline Monday & $61,2 \% *$ & $71,2 \% *$ & $56,3 \%$ \\
\hline Tuesday & $55,1 \%$ & $64,3 \% *$ & $49,9 \%$ \\
\hline Wednesday & $55,7 \%$ & $63,2 \% *$ & $48,2 \%$ \\
\hline Thursday & $56,3 \% *$ & $59,7 \%$ & $51,3 \% *$ \\
\hline Friday & $55,4 \%$ & $65,9 \% *$ & $52,9 \% *$ \\
\hline Saturday & $51,7 \% *$ & $56,4 \%$ & $50,8 \% *$ \\
\hline
\end{tabular}

$* \mathrm{p}<.01$ in t-test with simulation-based prediction

Outputs from the serious game delivered that the average utilization for nurses would fall below $85 \%$ in all scenarios. In the baseline scenario, the highest average utilization occurred on Monday, reaching 69\%. As Table 14 presents, in the first operative scenario, the utilization values increased to the $60 \%$-level. Only in the second operative scenario, the figure would reach above $70 \%$. The serious game with human plays, therefore, suggested that nurses were much less overloaded. 
Table 14. Impacts of serious gaming on the average utilization of nurses in the blue module.

\begin{tabular}{c|c|c|c}
\hline Day of week & Operative scenario 1 & Operative scenario 2 & Operative scenario 3 \\
\hline Sunday & $63,6 \% *$ & $69,3 \% *$ & $63,1 \%$ \\
\hline Monday & $64,3 \% *$ & $73,6 \% *$ & $64,3 \% *$ \\
\hline Tuesday & $55,7 \%$ & $65,4 \% *$ & $53,5 \%$ \\
\hline Wednesday & $56,9 \%$ & $61,3 \% *$ & $52,9 \%$ \\
\hline Thursday & $62,3 \%$ & $63,4 \% *$ & $54,3 \%$ \\
\hline Friday & $61,0 \%$ & $64,2 \% *$ & $53,6 \%$ \\
\hline Saturday & $60,5 \% *$ & $69,9 \% *$ & $58,5 \%$ \\
\hline
\end{tabular}

*p<.01 in t-test with simulation-based prediction

The time per patient to visit the doctor and length of stay reduced in general, associating almost 2 hours for the majority of the weekdays. Mean waiting time and overall length of stay were improving directionally appropriate compared to the industrial simulation forecasting. Especially in the second operative scenario, the management in the serious game delivered average lead time and patient lengths of stay in smaller values. Table 15 shows that the average lead time to a doctor would be marginally over 2 hours for the first and third operative. In scenarios of patient flow changes only, average waiting time for first examination from a physician was shorter than 2.5 hours. At a $20 \%$ flow increase, it is recognized that the average length of stay will not exceed 4 hours for the majority of the week. Only Wednesday engaged an average length of stay slightly over the 4-hour limit, as Table 16 summarized from the players.

Table 15. Impacts of serious gaming on the average lead time of seeing a doctor in the ED (in hours).

\begin{tabular}{c|c|c|c}
\hline Day of week & Operative scenario 1 & Operative scenario 2 & Operative scenario 3 \\
\hline Sunday & $2,23 *$ & $2,49 *$ & $2,13 *$ \\
\hline Monday & 2,11 & 2,18 & 1,99 \\
\hline Tuesday & 2,02 & $2,23 *$ & 1,97 \\
\hline Wednesday & 2,08 & 2,27 & 2,05 \\
\hline Thursday & 1,95 & 1,98 & 1,82 \\
\hline Friday & 2,01 & $2,12 *$ & 1,91 \\
\hline Saturday & 2,18 & 2,39 & 2,12 \\
\hline
\end{tabular}

$* \mathrm{p}<.01$ in t-test with simulation-based prediction

Table 16. Impacts of serious gaming on the average length of stay in the ED (in hours).

\begin{tabular}{c|c|c|c}
\hline Day of week & Operative scenario 1 & Operative scenario 2 & Operative scenario 3 \\
\hline Sunday & $3,56 *$ & $3,99 *$ & $3,41 *$ \\
\hline Monday & 3,62 & $3,91 *$ & 3,51 \\
\hline Tuesday & 3,62 & $3,98 *$ & 3,53 \\
\hline Wednesday & 3,67 & 4,04 & 3,62 \\
\hline Thursday & 3,58 & $3,69 *$ & 3,49 \\
\hline Friday & 3,66 & $4,00 *$ & 3,48 \\
\hline Saturday & 3,64 & $3,92 *$ & 3,50 \\
\hline
\end{tabular}

$* \mathrm{p}<.01$ in t-test with simulation-based prediction 
pag. 72

\section{Discussion and conclusion}

Simulations of ED management examine the extent to which the investigated system responds to patient inflow scenarios. However, the level of simulation is not at looking into what are actually delivered by ED employees. Furthermore, previous papers in this field were limited to incorporating humans in the loop and considering the impact of players' non-technical analytical skills on system performance.

\subsection{Methodological and modelling recommendations}

The findings of this paper concurrence that a serious game could be designed to reflect the logistical features of the ED and to facilitate the players improve the work performance of the system based on detailed information on patient inflow, tasks and resources. The core principle of strategic resource management is that resource availability needs to be prioritized to meet the medical needs of patients. This study proposes the processsimulation documents, which is adapted to the involvement of clinical and leadership experts in the problems of emergency departments, to organize the work system into activity-based components that do not widely exist in the literature. These documents describe the interaction between the work system and patient flow using multiple existing data sources.

A challenging serious game is designed based on the complex processes in health service provision and by a large number of artificial agents which allows for simulating tasks that are assigned to certain types of personnel. The proposed serious game method is then compared with pure simulation-based technological forecasting that implements only the scenarios but ignores human participation in the loop. The results show that our serious game method can incorporate the player - using complex system simulation and selected game mechanics - and leads to improved ED performance as a different outcome than pure simulation predictions. The main contribution of this study from a scientific perspective is that it supports gaming and simulation in the field of ED management yet demonstrates that serious gaming could enrich simulation results. The only previous paper that distinguishes this is a serious game-based revenue prediction study from Tantawichien et al [53]. By enhancing previous modelling methods, the complexity of an ED working environment could be established in a virtual environment, and its performance could be evaluated.

Play Your Process has been one of advanced method for the development of a serious game based on BPMN models [38]. The complexity of the work system requires that the Play Your Process method be adapted slightly in order to realize the simulation of a service-based organization. This resulted the process-simulation mapping documents providing the basic principles of the using resource pools, the updated statistics and the communication between agent models, as there has been no such detailed BPMN enterprise modeling of emergency care before. The entire serious game as presented via this link was built manually, given that AnyLogic, which is comparable to many other industrial simulation solutions, provides no automatic transfer from BPMN documents to executable simulations. However, based on the documents, it should be feasible to map with the libraries' building blocks delegating the various skeleton phrases of the production functions. See a summary of the generalization in Table 17. 
Table 17. Symbolizing BPMN symbols in simulations and gaming elements

\begin{tabular}{|c|c|c|c|c|}
\hline Element & Unity 3D & AnyLogic & FlexSim & Simul8 \\
\hline $\begin{array}{c}\Perp \\
\text { Shareholders }\end{array}$ & Humanoid Rigid Body & $\begin{array}{l}\text { Drag-and-drop } \\
\text { agents or } \\
\text { programmable } \\
\text { classes }\end{array}$ & $\begin{array}{l}\text { FlexScript, } \\
\text { C++, or } \\
\text { ProcessFlow }\end{array}$ & Visual Logic \\
\hline Starter & Animator in $\mathrm{C} \#$ & $\begin{array}{l}\text { Drag-and-drop } \\
\text { sources }\end{array}$ & Flow items & $\begin{array}{l}\text { Drag-and-drop } \\
\text { startpoints }\end{array}$ \\
\hline Final point & Animator in $\mathrm{C} \#$ & $\begin{array}{l}\text { Drag-and-drop } \\
\text { sinks }\end{array}$ & $\begin{array}{l}\text { Drag-and- } \\
\text { drop sinks }\end{array}$ & $\begin{array}{l}\text { Drag-and-drop } \\
\text { sinks }\end{array}$ \\
\hline Journal & - & $\begin{array}{c}\text { Tables, } \\
\text { hashmaps }\end{array}$ & - & - \\
\hline$\Leftrightarrow$ & - & $\begin{array}{l}\text { Variables, } \\
\text { parameters }\end{array}$ & - & - \\
\hline Connections & Animator in $\mathrm{C} \#$ & $\begin{array}{l}\text { Drag-and-drop } \\
\text { sinks, agent } \\
\text { connections }\end{array}$ & $\begin{array}{l}\text { Drag-and- } \\
\text { drop sinks }\end{array}$ & $\begin{array}{l}\text { Drag-and-drop } \\
\text { sinks }\end{array}$ \\
\hline Select & Animator in $\mathrm{C} \#$ & $\begin{array}{l}\text { Drag-and-drop } \\
\text { select outputs }\end{array}$ & $\begin{array}{l}\text { Drag-and- } \\
\text { drop select } \\
\text { outputs }\end{array}$ & $\begin{array}{l}\text { Drag-and-drop } \\
\text { select outputs }\end{array}$ \\
\hline
\end{tabular}

\subsection{Practical implications and suggestions}

Decision makers and managers need to be aware of the capabilities and limitations of simulation-based technological forecasting for handling logistical issues in hospitals when assessing various scenarios and the impact of system changes on system performance. Shortening the operating hours will not benefit the emergency department on the operational side, whilst incorporating human participation in simulation could serve as a basis for more objective system design and management. An inadequate representation of the manager could potentially underestimate the system's functionality for handling stressful situations and therefore produce poor decision making. Nevertheless, patient inflow is still detrimental to system performance. The managers need to carefully coordinate how patients will be treated in hospitals of the regional network.

The flow must be compatible with the capacity of the working system and handle various tasks without excessive workload, increasing the average length of stay and waiting times. Flow needs to be devised to with an accountability of the workload in the departments of the healthcare organization. Outputs from the serious game presented that a patient flow multiplier of $120 \%$ would produce nurse utilization above $90 \%$ for the busiest days, meanwhile shortening the work hours as well as reducing inflows did not benefit the emergency department on the operational side.

The managers need to carefully coordinate on how patients will be treated in hospitals of the regional network. The potential for primary care should be considered in order to adequately address ED crowding. However, current research evidence suggests that there are many challenges to engage with in the ED working environment [3]. This work, therefore, provides a starting point for the development of decision support tools to conduct imbalance settlement between patient flows and human resource practices. 
pag. 74

It needs to be pointed out that here, logistics management in health is mainly patientcentered rather than provider-centered in the sense that patients receive timely emergency care with human health resources. In that context, resource utilizations could be neglected. Low resource availability often yields accessibility problems. Therefore, in reality, it is necessary to deploy appropriate resource management strategies to avoid preventable high resource utilizations that might cause access blocks. Lessons could be learned from the logistics sector, where guidelines suggest that the optimal availability of a resource pool is at an $85 \%$ utilization occupancy [40][54]. Levy et al. demonstrated how a utilization above $92-93 \%$ results in a sharp increase in cruising time using a simulation study [55]. However, such resource utilization standards rarely exist in health services research. Although empirical data rarely presents an average utilization larger than $85 \%$, our study suggests that utilization of resources in healthcare logistics should not exceed $80 \%$, a level that will lead to overcrowding issues.

\subsection{Limitations and outlook}

This study is subject to limitations. First, with simulated work system mechanisms, we do not account for team dynamics and leadership in working environments. Certain aspects from participation of interprofessional teams are still not covered, such as the rationale for managing crew resources and the way the planning of in-ward staffing requirements differs across hospitals. Human errors and the health of clinical professionals, as affected by patient inflow, are not accounted for due to the scope of this study. We therefore suggest some modeling changes made with further game-based tests in addition to mirroring actual activities from empirical data. More operational data besides a single year of operation in 2017 will be collected to improve the details of the model and the accuracy of the analytical results. The serious game design includes a validation step; however, the portability of process-simulation mapping documents in engines rather than AnyLogic are not investigated. Last but not least, the relationships of logistical indicators are neither elucidated in the serious gaming outcomes nor in empirical demonstrations. It is expected a $20 \%$ increase in patient inflow to increase the logistical indicators by $20 \%$. In this study, however, the logistical indicator increase was larger than inflow increase.

The next planned step is to develop the business model to include a census in the wards as well as to introduce contingencies such as some patients needing to be cared for at a certain unit close to the Pediatric Intensive Care Unit or need surgical or orthopedic resources in the operational room. The relationship between flow and logistical indicators need to be investigated on whether logistical metrics proportionally are related to the patient load. It should be reminded that a purely quantitative approach to human resource management, especially in the healthcare sector, is reductive. Therefore quantitative measurements should be integrated with intuitive knowledge, which is fulfilled by participation from subject matter experts. A game engine needs to be utilized in order to compare the strengths and shortcomings of integrated development solutions in the simulation of complex processes. The limitations require the development of a more explicit representation of coordination from management nurses. Future research should consider the networked behaviors of all management employees - many of them could be different-situated in the ED - and their team working processes.

\section{Acknowledgement:}

The authors are grateful to Astrid Lindgren Children's Hospital, Karolinska University Hospital, who provided the data that allowed this analysis. We would especially like to thank Anna Bosaeus from the Pediatric Emergency Department. The authors state no conflicts of interests. 


\section{References}

[1] K. Wrenn, B. Lorenzen, I. Jones, C. Zhou, and D. Aronsky, "Factors affecting stress in emergency medicine residents while working in the ED," The American Journal of Emergency Medicine, vol. 28, no. 8, pp. 897-902, Oct. 2010. https://doi.org/10.1016/j.ajem.2009.05.001

[2] J. Crilly, J. Greenslade, C. Lincoln, J. Timms, and A. Fisher, "Measuring the impact of the working environment on emergency department nurses: A cross-sectional pilot study," International Emergency Nursing, vol. 31, pp. 9-14, Mar. 2017. https://doi.org/10.1016/j.ienj.2016.04.005

[3] U. E. Johansson, A. K. Johansson, and A. Grimby, "Psychosocial Workload of Swedish Ambulance and Emergency Room Personnel with High Prevalence of Dying, Death and Grieving Relatives. A Descriptive and Comparison Study," American Journal of Nursing Science, vol. 3, no. 5, p. 56, Sep. 2014. https://doi.org/10.11648/j.ajns.20140305.11

[4] Väntetider och patientflöden på akutmottagningar, Rapport februari 2017." Socialstyrelsen.

[5] C. Morley, M. Unwin, G. M. Peterson, J. Stankovich, and L. Kinsman, "Emergency department crowding: A systematic review of causes, consequences and solutions," PLoS One, vol. 13, no. 8, Aug. 2018.https://doi.org/10.1371/journal.pone.0203316

[6] "The State of Health in the EU: Companion Report 2017." European Commission.

[7] T. V. V. Batista, L. dos S. Machado, A. M. G. Valença, and R. M. de Moraes, "FarMyo: A Serious Game for Hand and Wrist Rehabilitation Using a Low-Cost Electromyography Device," Int. J. Serious Games, vol. 6, no. 2, pp. 3-19, Jun. 2019.https://doi.org/10.17083/ijsg.v6i2.290

[8] M. Salovaara-Hiltunen, K. Heikkinen, and J.-M. Koivisto, "User experience and learning experience in a 4D virtual reality simulation game," Int. J. Serious Games, vol. 6, no. 4, pp. 49-66, Nov. 2019.https://doi.org/10.17083/ijsg.v6i4.305

[9] A. Pyae et al., "Lessons Learned from Two Usability Studies of Digital Skiing Game with Elderly People in Finland and Japan," Int. J. Serious Games, vol. 4, no. 4, Dec. 2017.https://doi.org/10.17083/ijsg.v4i4.183

[10] S. Arora, L. Hull, M. Fitzpatrick, N. Sevdalis, and D. J. Birnbach, "Crisis Management on Surgical Wards: A Simulation-based Approach to Enhancing Technical, Teamwork, and Patient Interaction Skills," Annals of Surgery, vol. 261, no. 5, pp. 888-893, May 2015.https://doi.org/10.1097/SLA.0000000000000824

[11] L. Meurling, L. Hedman, C. Sandahl, L. Felländer-Tsai, and C.-J. Wallin, "Systematic simulation-based team training in a Swedish intensive care unit: a diverse response among critical care professions," BMJ Qual Saf, vol. 22, no. 6, pp. 485-494, Jun. 2013.https://doi.org/10.1136/bmjqs-2012-000994

[12] Y. Zhonggen, "A Meta-Analysis of Use of Serious Games in Education over a Decade," International Journal of Computer Games Technology, 2019.https://doi.org/10.1155/2019/4797032

[13] L. J. Abraham et al., "Morale, stress and coping strategies of staff working in the emergency department: A comparison of two different-sized departments," Emergency Medicine Australasia, vol. 30, no. 3, pp. 375-381, 2018.https://doi.org/10.1111/17426723.12895

[14] A. H. M. Pedersen, K. Rasmussen, R. Grytnes, and K. J. Nielsen, "Collaboration and patient safety at an emergency department - a qualitative case study," $\mathrm{J}$ of Health Org and Mgt, vol. 32, no. 1, pp. 25-38, Jan. 2018.https://doi.org/10.1108/JHOM-09-2016-0174

[15] C. Zhang, T. Grandits, K. P. Härenstam, J. B. Hauge, and S. Meijer, "A systematic literature review of simulation models for non-technical skill training in healthcare logistics," Advances in Simulation, vol. 3, no. 1, p. 15, Jul. 2018.https://doi.org/10.1186/s41077-0180072-7

[16] G. Fragapane, C. Zhang, F. Sgarbossa, and J. O. Strandhagen, "An Agent-Based Simulation Approach To Model Hospital Logistics," International Journal of Simulation Modelling, vol. 18, no. 4, pp. 654-665, Dec. 2019.https://doi.org/10.2507/IJSIMM18(4)497

[17] C.-H. Houze-Cerfon, C. Vaissié, L. Gout, B. Bastiani, S. Charpentier, and D. Lauque, "Development and Evaluation of a Virtual Research Environment to Improve Quality of Care in Overcrowded Emergency Departments: Observational Study," JMIR Serious Games, vol. 7, no. 3, Aug. 2019.https://doi.org/10.2196/13993

[18] S. S. W. Lam, C. B. L. Ng, F. N. H. L. Nguyen, Y. Y. Ng, and M. E. H. Ong, "Simulationbased decision support framework for dynamic ambulance redeployment in Singapore," International Journal of Medical Informatics, vol. 106, pp. 37-47, Oct. 2017.https://doi.org/10.1016/j.ijmedinf.2017.06.005

[19] C. J. van Oostveen, D. T. Ubbink, M. A. Mens, E. A. Pompe, and H. Vermeulen, "Preimplementation studies of a workforce planning tool for nurse staffing and human resource management in university hospitals," Journal of Nursing Management, vol. 24, no. 2, pp. 184-191, 2016.https://doi.org/10.1111/jonm.12297 
[20] D. Greenfield, A. Kellner, K. Townsend, A. Wilkinson, and S. A. Lawrence, "Health service accreditation reinforces a mindset of high-performance human resource management: lessons from an Australian study," Int J Qual Health Care, vol. 26, no. 4, pp. 372-377, Aug. 2014.https://doi.org/10.1093/intahc/mzu039

[21] M. Dobbins, K. DeCorby, P. Robeson, H. Husson, D. Tirilis, and L. Greco, "A knowledge management tool for public health: health-evidence.ca," BMC Public Health, vol. 10, no. 1, p. 496, Aug. 2010.https://doi.org/10.1186/1471-2458-10-496

[22] S. Meijer, "The Power of Sponges: Comparing High-Tech and Low-Tech Gaming for Innovation," Simulation \& Gaming, vol. 46, no. 5, pp. 512-535, Oct. 2015.https://doi.org/10.1177/1046878115594520

[23] S. Oyamada and S. Kitani, "Consensus Building Gaming Which Promotes Creative Solutions to Wildlife Management Dilemmas," Simulation \& Gaming, vol. 50, no. 5, pp. 556571, Oct. 2019.https://doi.org/10.1177/1046878119867366

[24] M. Batko, "Business Management Simulations - a detailed industry analysis as well as recommendations for the future," International Journal of Serious Games, vol. 3, no. 2, Jun. 2016.https://doi.org/10.17083/ijsg.v3i2.99

[25] O. Olsson and H. Aronsson, "Logistik för hälso och sjukvården." Linköpings universitet.

[26] A. Codrington-Virtue, T. Chaussalet, P. Millard, P. Whittlestone, and J. Kelly, "A System for Patient Management Based Discrete-Event Simulation and Hierarchical Clustering," in 19th IEEE Symposium on Computer-Based Medical Systems, 2006, pp. 800804.https://doi.org/10.1109/CBMS.2006.31

[27] J. Haugen and D. Nilsson, "Simulering av patientflödet på Vrinnevisjukhusets akutmottagning." Institutionen för teknik och naturvetenskap, Linköpings universitet.

[28] M. Pitt, T. Monks, S. Crowe, and C. Vasilakis, "Systems modelling and simulation in health service design, delivery and decision making," BMJ Quality \& Safety, vol. 25, no. 1, pp. 3845, Jan. 2016.https://doi.org/10.1136/bmjqs-2015-004430

[29] R. S. Maull, P. A. Smart, A. Harris, and A. A.-F. Karasneh, "An evaluation of 'fast track' in A\&E: a discrete event simulation approach," The Service Industries Journal, vol. 29, no. 7, pp. 923-941, Jul. 2009.https://doi.org/10.1080/02642060902749534

[30] J. Bowers, M. Ghattas, and G. Mould, "Success and failure in the simulation of an Accident and Emergency department," Journal of Simulation, vol. 3, no. 3, pp. 171-178, Sep. 2009.https://doi.org/10.1057/jos.2009.5

[31] C. Zhang and S. Meijer, "A Simulation Game of Patient Transportation," in Neo-Simulation and Gaming Toward Active Learning, vol. 18, R. Hamada, S. Soranastaporn, H. Kanegae, P. Dumrongrojwatthana, S. Chaisanit, P. Rizzi, and V. Dumblekar, Eds. Springer Singapore, 2019.

[32] Effektiv vård: slutbetänkande. Stockholm: Wolters Kluwer, 2016.

[33] P. Mazzocato et al., "Complexity complicates lean: lessons from seven emergency services.," Journal of health organization and management, vol. 28, no. 2, pp. 266-288, 2014.https://doi.org/10.1108/JHOM-03-2013-0060

[34] J. G. Cronin, "The introduction of the Manchester triage scale to an emergency department in the Republic of Ireland," Accident and Emergency Nursing, vol. 11, no. 2, pp. 121-125, Apr. 2003.https://doi.org/10.1016/S0965-2302(02)00218-7

[35] H. Scheuerlein et al., "New methods for clinical pathways-Business Process Modeling Notation (BPMN) and Tangible Business Process Modeling (t.BPM)," Langenbeck's Archives of Surgery, vol. 397, no. 5, pp. 755-761, Jun. 2012.https://doi.org/10.1007/s00423012-0914-z

[36] M. G. C. A. Cimino, F. Palumbo, G. Vaglini, E. Ferro, N. Celandroni, and D. La Rosa, "Evaluating the impact of smart technologies on harbor's logistics via BPMN modeling and simulation," Inf Technol Manag, vol. 18, no. 3, pp. 223-239, Sep. 2017.https://doi.org/10.1007/s10799-016-0266-4

[37] T. M. de Classe, R. M. D. Araujo, G. B. Xexéo, and S. Siqueira, "The Play Your Process Method for Business Process-Based Digital Game Design," 1, vol. 6, no. 1, pp. 27-48, Mar. 2019.https://doi.org/10.17083/ijsg.v6i1.269

[38] "AnyLogic: Simulation Modeling Software Tools \& Solutions for Business." [Online]. Available: https://www.anylogic.com/. [Accessed: 07-Jun-2019].

[39] A. Borshchev, Y. Karpov, and P. Lebedev, "Distributed Simulation of Hybrid Systems with HLA Support," in Parallel Computing Technologies, vol. 2127, V. Malyshkin, Ed. Berlin, Heidelberg: Springer Berlin Heidelberg, 2001, pp. 410-420.https://doi.org/10.1007/3-54044743-1_42

[40] O. Cats, C. Zhang, and A. Nissan, "Survey methodology for measuring parking occupancy: Impacts of an on-street parking pricing scheme in an urban center," Transport Policy, vol. 47, pp. 55-63, Apr. 2016.https://doi.org/10.1016/j.tranpol.2015.12.008

[41] S. Arnab et al., "Mapping learning and game mechanics for serious games analysis: Mapping learning and game mechanics," Br J Educ Technol, vol. 46, no. 2, pp. 391-411, Mar. 2015.https://doi.org/10.1111/bjet.12113 
[42] E. Deci and R. M. Ryan, Intrinsic Motivation and Self-Determination in Human Behavior. Springer, 1985.https://doi.org/10.1007/978-1-4899-2271-7

[43] W. Abo-Hamad and A. Arisha, "Simulation-based framework to improve patient experience in an emergency department," European Journal of Operational Research, vol. 224, no. 1, pp. 154-166, Jan. 2013.https://doi.org/10.1016/j.ejor.2012.07.028

[44] R. Carmen, M. Defraeye, and I. Van Nieuwenhuyse, "A Decision Support System for Capacity Planning in Emergency Departments," Int. J. Simul. Model, vol. 14, no. 2, pp. 299312, Jun. 2015.https://doi.org/10.2507/IJSIMM14(2)10.308

[45] M. A. Ahmed and T. M. Alkhamis, "Simulation optimization for an emergency department healthcare unit in Kuwait," European Journal of Operational Research, vol. 198, no. 3, pp. 936-942, Nov. 2009.https://doi.org/10.1016/j.ejor.2008.10.025

[46] J. Banks, J. S. Carson, B. L. Nelson, and D. M. Nicol, Discrete-Event System Simulation. Pearson Education Limited, 2013.

[47] R. Khalid, W. Kreutzer, and T. Bell, "Combining Simulation and Animation of Queueing Scenarios in a Flash-Based Discrete Event Simulator," in Information Systems: Modeling, Development, and Integration, vol. 20, J. Yang, A. Ginige, H. C. Mayr, and R.-D. Kutsche, Eds. Berlin, Heidelberg: Springer Berlin Heidelberg, 2009, pp. 240251.https://doi.org/10.1007/978-3-642-01112-2_25

[48] R. G. Sargent, "Verification and validation of simulation models," Journal of Simulation, vol. 7, no. 1, pp. 12-24, Feb. 2013.https://doi.org/10.1057/jos.2012.20

[49] C. Zhang, K. P. Härenstam, J. Nordquist, and S. Meijer, "Structuring game design with active learning benefits: insights from logistical skills training in managing an emergency department," in Simulation and gaming through times and across disciplines, Kozminski University.

[50] J. B. Jun, S. H. Jacobson, and J. R. Swisher, "Application of Discrete-Event Simulation in Health Care Clinics: A Survey," The Journal of the Operational Research Society, vol. 50, no. 2, p. 109, Feb. 1999.https://doi.org/10.2307/3010560

[51] C. F. Rusnock, E. W. Maxheimer, K. F. Oyama, and V. V. Valencia, "Simulation-Based Evaluation of the Effects of Patient Load on Mental Workload of Healthcare Staff," Simulation in Healthcare: The Journal of the Society for Simulation in Healthcare, vol. 12, no. 4, pp. 260-267, Aug. 2017.https://doi.org/10.1097/SIH.0000000000000248

[52] "World Medical Association Declaration of Helsinki. Ethical principles for medical research involving human subjects," Bull World Health Organ, vol. 79, no. 4, pp. 373-374, 2001"

[53] J. Tantawichien, H. Mizuyama, and T. Nonaka, "Designing a Human Computation Game for Enhancing Early-Phase Movie Box Office Prediction," in Neo-Simulation and Gaming Toward Active Learning, R. Hamada, S. Soranastaporn, H. Kanegae, P. Dumrongrojwatthana, S. Chaisanit, P. Rizzi, and V. Dumblekar, Eds. Singapore: Springer, 2019, pp. 13-22.https://doi.org/10.1007/978-981-13-8039-6_2

[54] T. Litman, "Parking Pricing Implementation Guide," Victoria Transport Policy Institute, 2018.

[55] N. Levy, K. Martens, and I. Benenson, "Exploring cruising using agent-based and analytical models of parking," Transportmetrica A: Transport Science, vol. 9, no. 9, pp. 773797, Oct. 2013.https://doi.org/10.1080/18128602.2012.664575 